\title{
Advanced Turbine Systems Program Conceptual Design and Product Development Task 3.0 \\ Selection of Natural Gas-Fired Advanced Turbine System
}

Topical Report

December 1994

Work Performed Under Contract No.: DE-AC21-93MC30247

For

U.S. Department of Energy

Office of Fossil Energy

Morgantown Energy Technology Center

Morgantown, West Virginia

By

Westinghouse Electric Corporation

Orlando, Florida 


\section{DISCLAIMER}

This report was prepared as an account of work sponsored by an agency of the United States Government. Neither the United States Government nor any agency thereof, nor any of their employees, makes any warranty, express or implied, or assumes any legal liability or responsibility for the accuracy, completeness, or usefulness of any information, apparatus, product, or process disclosed, or represents that its use would not infringe privately owned rights. Reference herein to any specific commercial product, process, or service by trade name, trademark, manufacturer, or otherwise does not necessarily constitute or imply its endorsement, recommendation, or favoring by the United States Government or any agency thereof. The views and opinions of authors expressed herein do not necessarily state or reflect those of the United States Government or any agency thereof.

This report has been reproduced directly from the best available copy.

Available to DOE and DOE contractors from the Office of Scientific and Technical Information, 175 Oak Ridge Turnpike, Oak Ridge, TN 37831; prices available at (615) 576-8401.

Available to the public from the National Technical Information Service, U.S. Department of Commerce, 5285 Port Royal Road, Springfield, VA 22161; phone orders accepted at (703) 487-4650. 


\section{DISCLAIMER}

Portions of this document may be illegible in electronic image products. Images are produced from the best available original document. 


\title{
Advanced Turbine Systems Program Conceptual \\ Design and Product Development \\ Task 3.0 \\ Selection of Natural Gas-Fired Advanced Turbine System
}

\author{
Topical Report \\ December 1994
}

Work Performed Under Contract No.: DE-AC21-93MC30247

For

U.S. Department of Energy

Office of Fossil Energy

Morgantown Energy Technology Center

P.O. Box 880

Morgantown, West Virginia 26507-0880

By

Westinghouse Electric Corporation

Emerging Business and Strategic Alliances

Power Generation Business Unit

4400 Alafaya Trail

Orlando, Florida 32826-2399

December 1994 


\section{CONTENTS}

$\underline{\text { Section }}$

Page

1 Introduction

$1-1$

2

Summary \& Conclusions

3

Cycle Analysis

3-1

4

Evaluation of Candidate Systems

4-1

5

High Temperature Developments

$5-1$

6

Critical Components and Barrier Issues

6-1

7

References

$7-1$

Appendix

A Capital Cost and COE Assumptions

A-1

B

Reliability, Availability, Maintainability

B-1 


\section{FIGURES \& TABLES}

Figure

$\underline{\text { Title }}$

Evolution of Large Westinghouse Gas Turbines

ATS Plant Layout

Gas Turbine Inlet Temperature Trend

High Temperature Engine Baseline Combined Cycle

Turbine Cooling and Leakage, Effect on Combined

Cycle Thermal Efficiency

Compressor Pressure Ratio, Effect on Thermal Efficiencies

Compressor Intercooling, Effect on Specific Output

Compressor Intercooling, Effect on Thermal Efficiencies

Intercooled, Aftercooled (Evaporative), Recuperative Combined Cycle

Thermochemical Recuperation Cycle with Steam Reforming

Table

Title

$\underline{\text { Page }}$

6-1

ATS Component Development Projects

6-4

A-1
A-1 


\begin{abstract}
This Topical Report presents the results of Task 3 of the Westinghouse ATS Phase II Program. The objective of Task 3 was to analyze and evaluate different cycles for the natural gas-fired Advanced Turbine Systems (GFATS) in order to select one that would achieve all of the ATS Program goals. Approximately 50 cycles, under five main groupings, were considered and evaluated on the basis of plant efficiency, emissions, cost of electricity, reliability-availability-maintainability (RAM), and program schedule requirements. The five main cycle concepts studied were:

- advanced combined cycle

- intercooled cycle

- recuperated cycle

- reheat cycle

- thermochemically recuperated cycle

The advanced combined cycle was selected for the ATS plant, because it was considered to have the highest potential for achieving all of the ATS Program goals by year 2000 . This advanced combined cycle plant will incorporate a technologically advanced gas turbine engine design, as well as improvements in the bottoming cycle and the generator. Detailed cost and RAM analyses were carried out on six selected cycle configurations and compared to the estimates for the Baseline Plant. Issues critical to the successful development of the Advanced Combined Cycle are identified and discussed in this report. The achievement of the plant efficiency and cost of electricity goals will require higher firing temperatures than today's standard and with minimized cooling of hot end components. This will necessitate the selection and/or development of new alloys and materials and improved coatings for the ATS engine. To ensure success of this program, a concerted development effort with technological advancements will be required in combustion, aerodynamic design, cooling design, mechanical design, leakage control, and materials/coating technologies.
\end{abstract}




\section{Section 1}

\section{INTRODUCTION}

The objective of Task 3 was to analyze and evaluate different cycles for the natural gasfired Advanced Turbine Systems (GFATS) in order to select one that would achieve all of the ATS Program goals. These goals are as follows:

- greater than $60 \%$ plant cycle efficiency (on LHV basis)

- $10 \%$ lower NOx emissions than current commercial values

- cost of electricity $10 \%$ less than current values

- RAM results comparable with current combined cycle plants

- demonstration by year 2000

Detailed cycle performance, cost of electricity, and RAM analysis were carried out to provide information on which the final selection of the GFATS cycle would be made. To achieve the very challenging goals, innovative approaches and technological advances are required, particularly in combustion, aerodynamic design, cooling design, mechanical design, leakage control, materials, and coating technologies.

The ATS engine will be the next model in the series of large heavy duty gas turbines developed by Westinghouse. Westinghouse has been involved in gas turbine design and development since 1945. During that time, Westinghouse engineers have made significant contributions in advancing gas turbine technology, especially in the field of heavy duty engines used in industrial and electrical utility applications. Some of the innovations included single shaft two bearing design, cold end drive, axial exhaust, cooled turbine airfoils in an industrial engine, and tilting pad bearings. The improvement in gas turbine performance and mechanical efficiency was both evolutionary, where small improvements were made continuously, and revolutionary, where new designs were produced to achieve a large step change in engine output power and efficiency, as well as mechanical integrity and reliability. Figure 1-1 shows the evolution of large operating industrial and utility gas turbines developed by Westinghouse. 


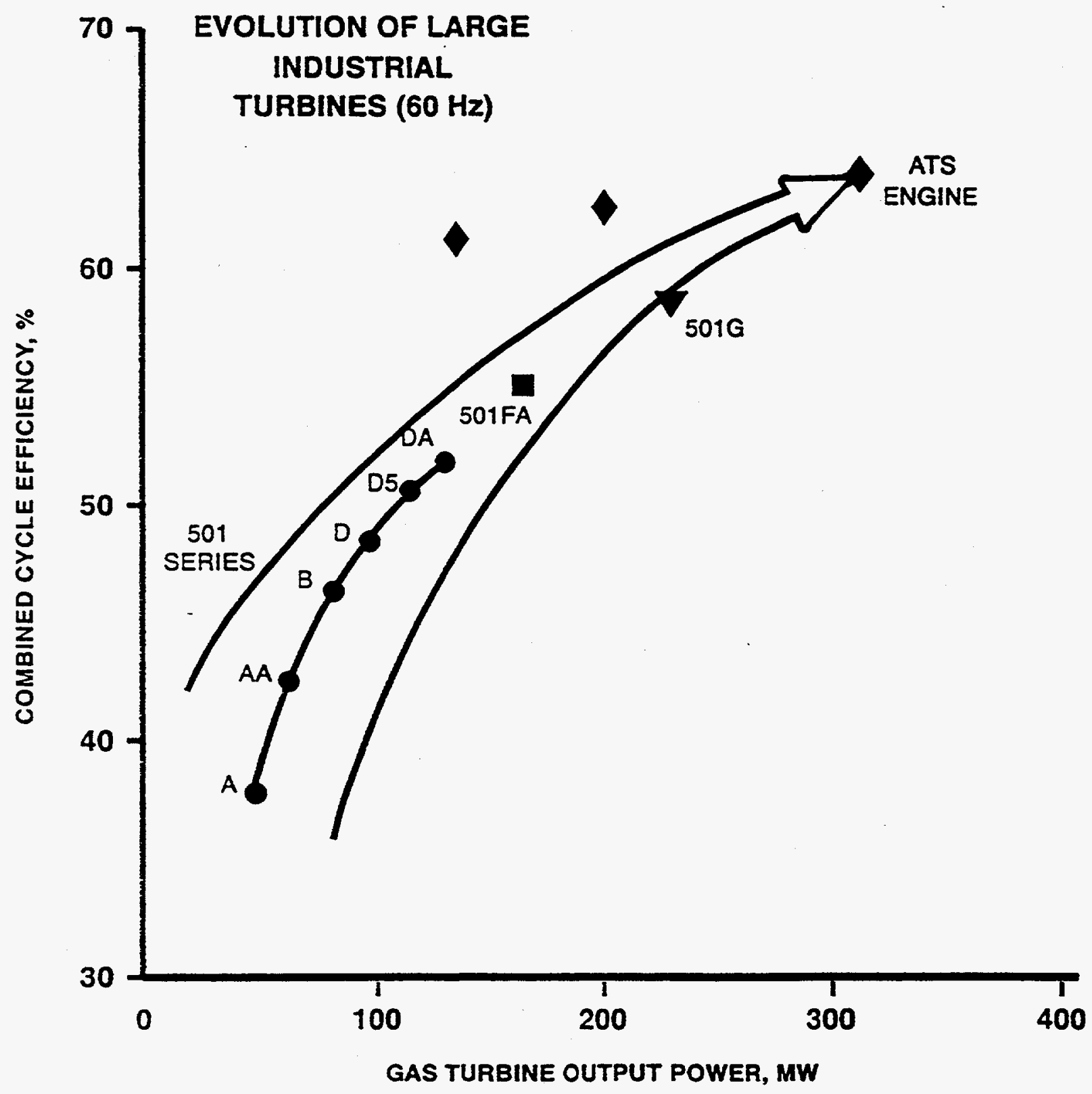

Figure 1-1. Evolution of Large Westinghouse Gas Turbines 


\section{Section 2}

\section{SUMMARY AND CONCLUSIONS}

Various cycles were considered and evaluated for the ATS Program on the basis of plant efficiency, emissions, cost of electricity, reliability-availability-maintainability (RAM), and program schedule requirements. The main cycle concepts investigated were the advanced combined cycle, intercooled, recuperated, reheat, and thermochemically recuperated cycles. The advanced combined cycle was selected for the ATS Program because it was considered to have the best potential for achieving all of the ATS Program goals by the year 2000 .

Detailed cost and RAM analyses were carried out on six selected cycle configurations and compared to the Westinghouse 501F combined cycle. These comparisons determined whether or not the evaluated cycles met the performance requirements of the ATS program.

The various cycles evaluated had combustion turbine inlet temperatures ranging from $2450^{\circ} \mathrm{F}$ to greater than $2750^{\circ} \mathrm{F}$; pressure ratios of $18: 1$ to $48: 1$; and power outputs of 243 MW to $339 \mathrm{MW}$. The advanced combined cycle selected will exceed all the ATS requirements and has a net plant output of $452 \mathrm{MW}$.

Issues critical to the successful development of the advanced combined cycle plant were identified. The achievement of the ATS plant cycle efficiency and cost of electricity goals will require higher engine firing temperatures with minimized cooling of hot end components. This, in turn, will necessitate the selection and/or development of new alloys, materials, casting processes, and coatings for the ATS engine. To ensure success of this program, a concerted development effort and technological advancements will be mandatory in combustion, aerodynamic design, cooling design, mechanical design, leakage control, and materials/coating technologies.

Based on the investigations described in this report, the following conclusions can be drawn:

1. Westinghouse plans to pursue an advanced combined cycle plant with the following features:

- Advanced aero/heat transfer/materials technology

- Burner outlet temperature in excess of $2730^{\circ} \mathrm{F}$

- Closed-loop steam cooling

- Single crystal and directional solidified airfoils

- Improved thermal barrier and anti-corrosion coatings

- Ceramic ring segments

- Active tip clearance control

- Brush seals 
- Reduced compressor dump/combustor loss

- Increased Row 4 blade exit area

- Reduced inlet and exhaust losses

- Fuel preheating

- All rotating turbine-generator power components on a single shaft

- Advanced steam turbine design technology

- $1800 \mathrm{psi} / 1100^{\circ} \mathrm{F} / 1100^{\circ} \mathrm{F}$ steam cycle

This advanced combined cycle power plant is designated as "ATS" throughout this report. Figure 2-1 shows the selected cycle.

2. Considerable effort will be required to develop technologies critical to the success of the ATS Program 


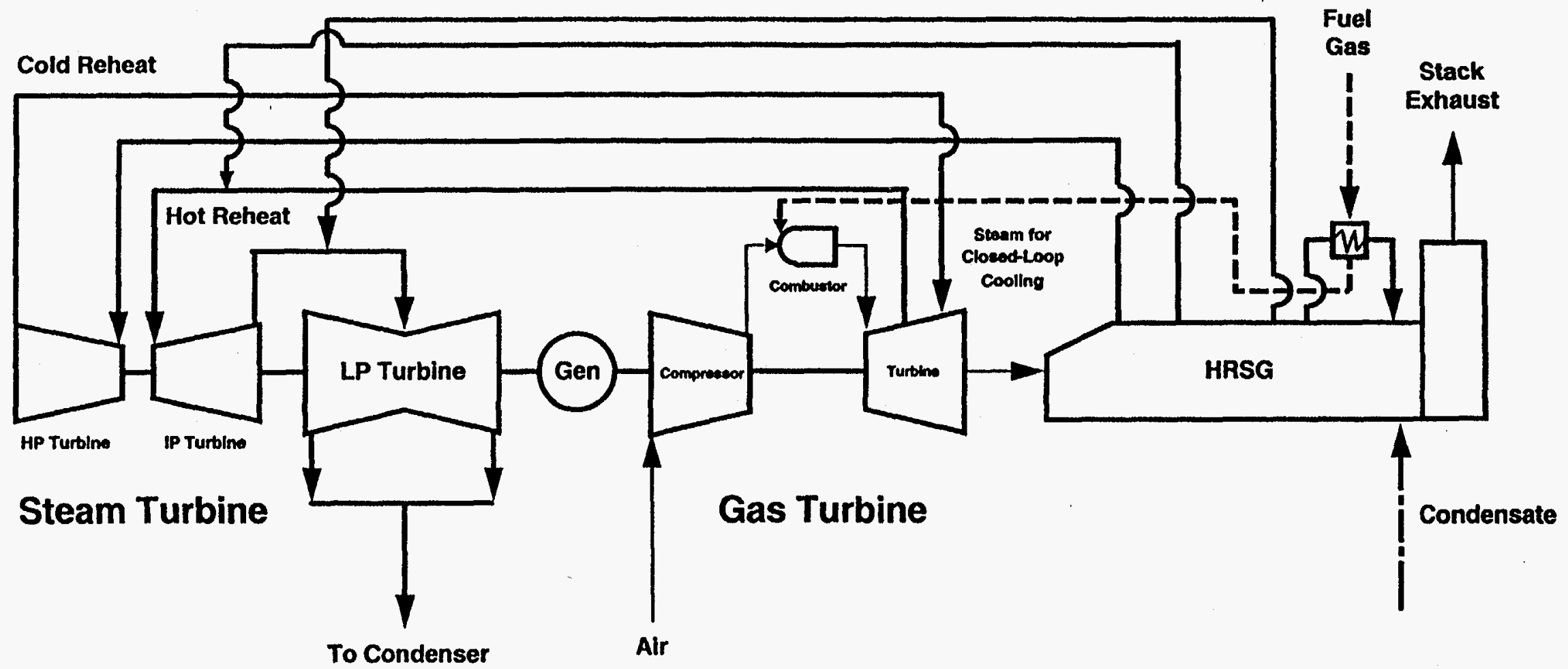

$$
\begin{array}{ll}
-\ldots & \text { Fuel Gas } \\
\hline & \text { Air / Gas } \\
& \text { Steam } \\
\ldots & \text { Water }
\end{array}
$$




\section{Section 3}

\section{CYCLE ANALYSIS}

Westinghouse has developed a product line that mirrors the general gas turbine inlet temperature trend shown in Figure 3-1. To make gas turbines competitive with steam turbine plants, it has been necessary to develop more efficient cycles. Over the years, Westinghouse has performed many engineering studies to determine optimum cycles to minimize the cost of electricity. Some of the more promising cycles (intercooled, multiple shafts, reheat, steam injected, and water injected at various locations) have been studied in detail (Scalzo et al., 1994). In the final analysis, the simple cycle gas turbine combined with a steam bottoming cycle (a synergistic combination of the Brayton and Rankine cycles) was developed to increase overall cycle efficiency. Stephens, (1952) and Baldwin et al., (1965), are two references which summarize previous Westinghouse work on optimizing plant cycle efficiency.

Current large natural gas-fired combined cycle power generation systems are capable of efficiency levels in excess of 54\%. Within the ATS program, Westinghouse has been given the opportunity to re-evaluate cycle efficiencies using proven, established concepts, such as intercooling and recuperation, and newer concepts, such as thermochemical recuperation (Little, Bannister, and Wiant, 1993). In addition, efficiency enhancements within the ATS selected cycle are to be evaluated to determine the best approaches to raising overall thermal plant efficiencies to greater than a net $60 \%$ while adhering to the other ATS program goals. The concepts considered in the Westinghouse analyses are to be capable of demonstration within a three to four year time frame. From a baseline cycle definition, this report discusses how different concepts will affect the overall plant thermal efficiency. Our analysis indicates that a plant efficiency of greater than $60 \%$ is achievable.

\section{BASELINE CYCLE}

In order to evaluate different technologies and concepts applicable to combined cycle power generation systems, a high temperature engine baseline combined cycle configuration first had to be developed to provide a basis for comparison of all the cycle concepts and technologies to be considered. For this purpose, a conventionally configured combustion turbine coupled with a three-pressure level reheat steam cycle (Figure 3-2) was modeled to provide a high temperature engine baseline combined cycle. The combustion turbine rotor inlet temperature (RIT) was set at $2600^{\circ} \mathrm{F}$ to approximate near-term temperature capabilities (Bannister et al., 1994). The compressor pressure ratio was set at 18 . High pressure steam conditions entering the steam turbine were specified at $1450 \mathrm{psi}$ and $1000^{\circ} \mathrm{F}$ and the hot reheat steam temperature was also set at $1000^{\circ} \mathrm{F}$. Note that this configuration utilizes turbine rotor cooling air heat to produce additional low pressure steam in the steam cycle via a heat exchanger located in the heat recovery steam generator (HRSG). Also, the natural gas fuel is preheated by feedwater recirculation flow. 


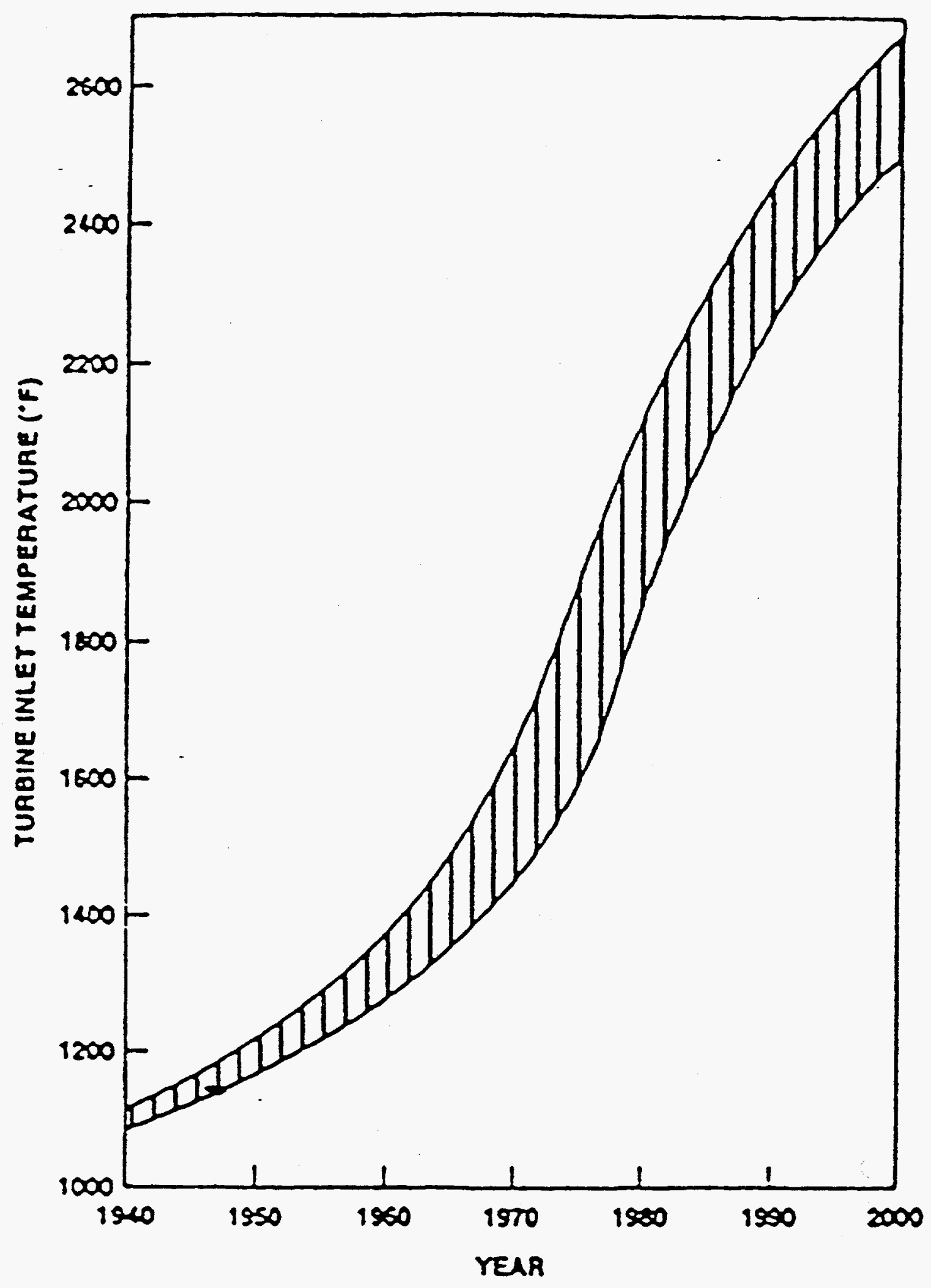

Figure 3-1. Gas Turbine Inlet Temperature Trend 


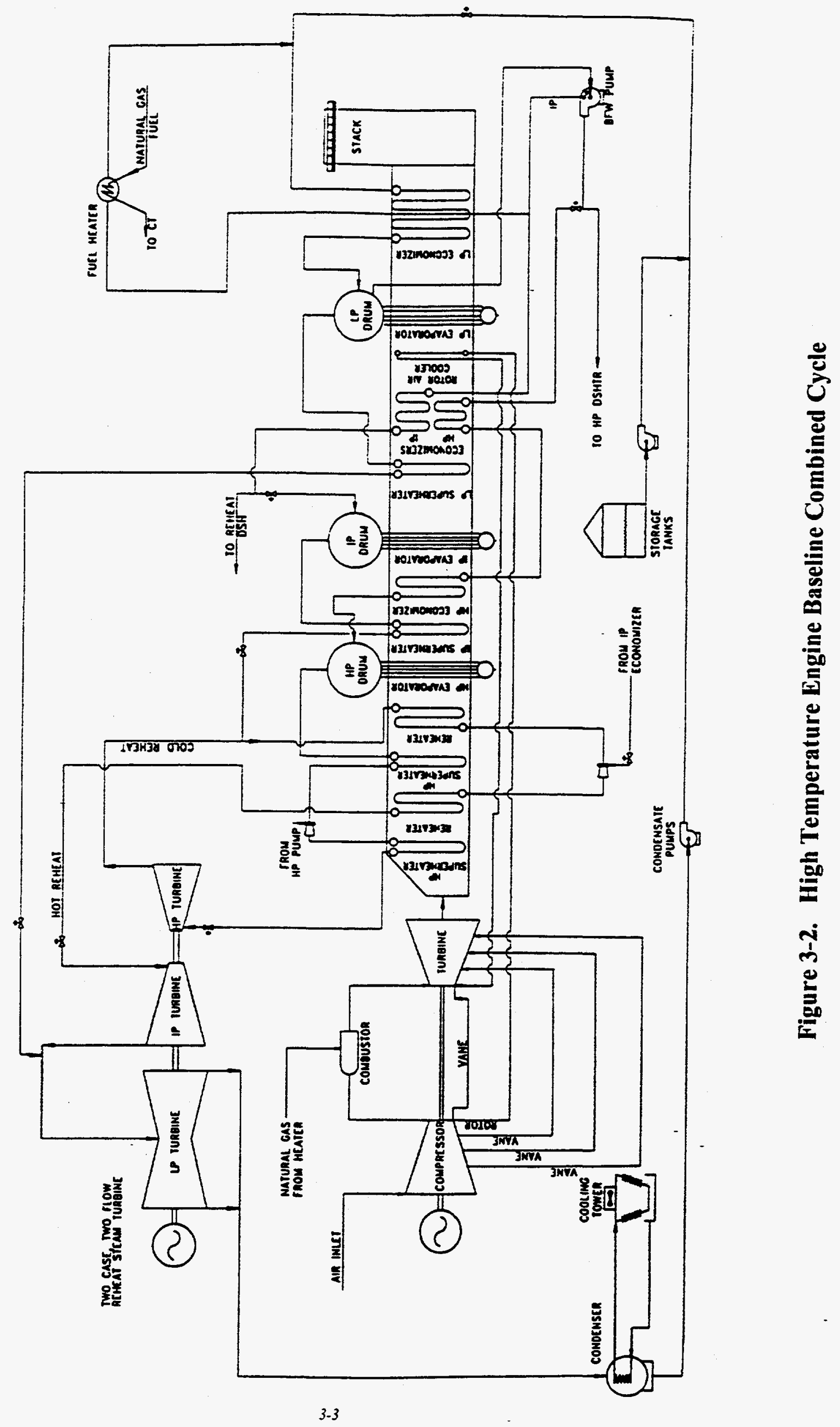


The ATS engine will be based on the proven technologies incorporated in the 501 frames. To exceed the ATS program plant cycle efficiency and emission goals, however, will require advancements in several key gas turbine technologies: closed-loop steam cooling, catalytic combustor components and advanced coating systems. Additional enhancements include advanced aerodynamic and sealing design active blade tip control, and materials and coatings with high-temperature capabilities.

\section{COMPONENT IMPROVEMENTS}

Incorporation of several component improvements, available through recent technological developments and advanced design techniques, into the power generation system of Figure 3-2 results in significant efficiency gains. The application of advanced design tools will enable the analysis and incorporation of design changes that will increase compressor and turbine efficiencies. Blade tip and seal leakages will be minimized to further enhance efficiency. Improved materials, including ceramic components, coatings, and cooling designs will be incorporated to reduce cooling requirements and improve cycle efficiency (see Section 6).

There are two generators in the high temperature baseline configuration. One of these is the combustion turbine generator, while the other is the steam turbine generator. Current generator designs are capable of higher efficiency than those chosen for the high temperature baseline cycle. While the combustion turbine generator of the high temperature baseline configuration is of sufficient size to cost effectively apply this technology, the steam turbine generator is not. By utilizing a single shaft arrangement, however, the smaller steam turbine generator is eliminated and the remaining single generator may be designed at the higher efficiency.

When the component improvements listed above are all incorporated into the high temperature baseline cycle, the net plant thermal efficiency is increased by approximately 2 percentage points.

\section{STEAM CYCLE ENHANCEMENTS}

The basic reason for raising the steam pressure and temperature of the Rankine cycle is to improve the potential thermal efficiency. The first cycle variations investigated within this study were modifications to the high temperature baseline cycle in which the steam cycle was enhanced (previous Westinghouse studies to optimize steam cycle configurations for subcritical and supercritical applications are summarized by Ernette and Silvestri, 1990, and Silvestri et al., 1992). The results of these studies indicated that increasing either high pressure steam superheat temperature or reheat steam temperature by $50^{\circ} \mathrm{F}$ results in an improvement in combined cycle thermal efficiency of 0.1 percentage point. Increasing high pressure steam pressure from $1450 \mathrm{psi}$ to $1800 \mathrm{psi}$ results in an increase in net plant thermal efficiency of 0.1 percentage point. A further increase in pressure to 2400 psi yields only an additional 0.05 percentage point in thermal efficiency, while adding to the cost of the high pressure steam system. Also, since the steam turbine size is set by the exhaust energy of the combustion turbine, increasing steam pressure 
reduces the blade heights in the high pressure steam turbine. For 2400 psig high pressure steam, the resulting blade heights are much smaller and less efficient than for the $1800 \mathrm{psi}$ steam. Therefore, the optimum steam cycle was determined to be at $1800 \mathrm{psi}$ with $1100^{\circ} \mathrm{F}$ high pressure superheat steam and $1100^{\circ} \mathrm{F}$ reheat steam (both $100^{\circ} \mathrm{F}$ above the baseline cycle temperature). This resulted in a 0.5 percentage point increase in net plant thermal efficiency and also in a slight increase in output due to the increased efficiency of the steam cycle. The steam temperatures were limited to $1100^{\circ} \mathrm{F}$ for this study due to steam turbine materials, reliability, and cost considerations. The steam temperature of $1100^{\circ} \mathrm{F}$ plus a reasonable steam superheater approach $\Delta \mathrm{T}$ is determined by the combustion turbine exhaust temperature and this, in turn, set the baseline cycle pressure ratio.

\section{ROTOR AIR COOLER HEAT UTILIZATION}

The Westinghouse 501F combustion turbine combined cycle provides two options for rotor air cooler heat utilization. The first option is an air-to-air cooler to cool the rotor cooling air after it exits the compressor and prior to its introduction into the rotor. The rotor air heat is rejected to the atmosphere via an air-to-air cooler. The other option is to cool the rotor air via an air-to-exhaust gas heat exchanger located in the HRSG upstream of the low pressure evaporator, as was done in the high temperature baseline cycle. With this configuration, the rotor air cooler heat is recovered by the steam cycle, which produces low pressure steam. This results in higher plant efficiency than that of the airto-air cooler method, since the rotor air cooler heat is recovered by the low pressure steam system.

Another concept involves removing the HRSG rotor air cooler used in the high temperature baseline configuration and installing a rotor air cooler which exchanges heat with the incoming natural gas fuel (after the fuel has been preheated). This returns the rotor air heat back to the combustion turbine, which then requires less fuel to achieve the desired rotor inlet temperature. Therefore, the rotor air heat is recovered at the combustion turbine efficiency (typically about $40 \%$ ), which is much higher than the low pressure steam system efficiency. This is, therefore, a much more effective recovery of the heat than is obtained via low pressure steam production, and results in an increase in net plant thermal efficiency of 0.4 percentage point over the high temperature baseline configuration.

\section{CLOSED-LOOP STEAM COOLING}

Most current gas turbine engines utilize air to cool the turbine vanes and blades. This allows the turbine inlet temperature to be increased beyond the temperature at which the turbine material can be used without cooling, thus increasing the cycle efficiency and power output. However, the cooling air itself is a detriment to cycle efficiency in four ways. First, it is ejected from the turbine airfoils, thereby causing a disruption in the surrounding flow field. This increases the airfoils' irreversible pressure losses and results in a reduction in turbine efficiency. Secondly, since the cooling air is ejected from the airfoil into the gas path, the resulting mixing of the cooling air into the gas path results in 
irreversible pressure losses due to the non-ideal mixing of the streams, which have very different velocity vectors. The third loss mechanism is caused by the reduction in gas path temperature that accompanies the mixing of the cooling air into the gas path. This reduction in temperature reduces the work output of the turbine and, therefore, compromises cycle efficiency. Finally, the turbine cooling air must be pumped to pressures significantly higher than that of the gas path pressure at the location it is injected. This is done to assure that the cooling flow rate will be sufficient during certain operating conditions where the ratio of coolant pressure to gas path pressure drops below its design level. While some of this pressure is recovered by the turbine, there are internal losses as the cooling air passes from the compressor to the turbine gas path. The additional pumping work required to raise the cooling air to the required pressure is the associated loss.

The effect of cooling air on cycle efficiency is shown in Figure 3-3. This figure shows the potential increase in combined cycle thermal efficiency for fractional reductions in cooling or leakage flows. In this figure, the lines labeled 'Fixed P/P' show the effect for fixed compressor pressure ratio (i.e., the turbine expander is increased in size to handle the additional flow resulting from the reduction in cooling or leakage) and the lines labeled 'Fixed Expander' show the effect for fixed expander size (the compressor pressure ratio is allowed to rise so that the additional flow caused by the reduction in cooling or leakage can be accommodated by a turbine of the original size). Note that, although turbine leakage generally carries a larger efficiency penalty than turbine cooling per given amount of flow, the fact that the amount of leakage flow is far less than the amount of cooling flow results in far less efficiency benefit from reducing turbine leakage flows a given fractional amount compared to reducing turbine cooling flows by the same fraction of their baseline value.

By using closed-loop steam cooling, the loss mechanisms described above can be largely eliminated, while still maintaining turbine material temperatures at acceptable levels. In combined cycles, the steam used for cooling the combustion turbine hot parts is usually taken from the steam bottoming cycle. This steam is then returned to the bottoming cycle after it has absorbed heat in the closed-loop steam cooling system. For an advanced bottoming steam cycle, closed-loop steam cooling would route cold reheat steam from the exit of the high pressure steam turbine to the combustion turbine vane casing and rotor. The steam is passed through passageways within the vane and rotor assemblies and through the vanes and rotors themselves, then collected and sent back to the steam cycle intermediate pressure steam turbine as hot reheat steam. This approach to turbine cooling relies solely on convective heat transfer. Since no steam or cooling fluid is ejected from the airfoils, aside from a small amount of steam leakage through the rotor seals, there is very little influence of the cooling steam on the airfoil flow fields, and hence minimal mixing losses. Also, the reduction in gas path temperature is minimized, since the convective heat flux across the airfoils is relatively small. Typically, first vane cooling air mixing reduces the gas path temperature approximately $100^{\circ} \mathrm{F}$ to $150^{\circ} \mathrm{F}$. For closedloop steam cooling however, the reduction in gas path temperature is only about $10^{\circ} \mathrm{F}$ to $15^{\circ} \mathrm{F}$, or one tenth of the reduction of conventional cooling techniques. Application of 


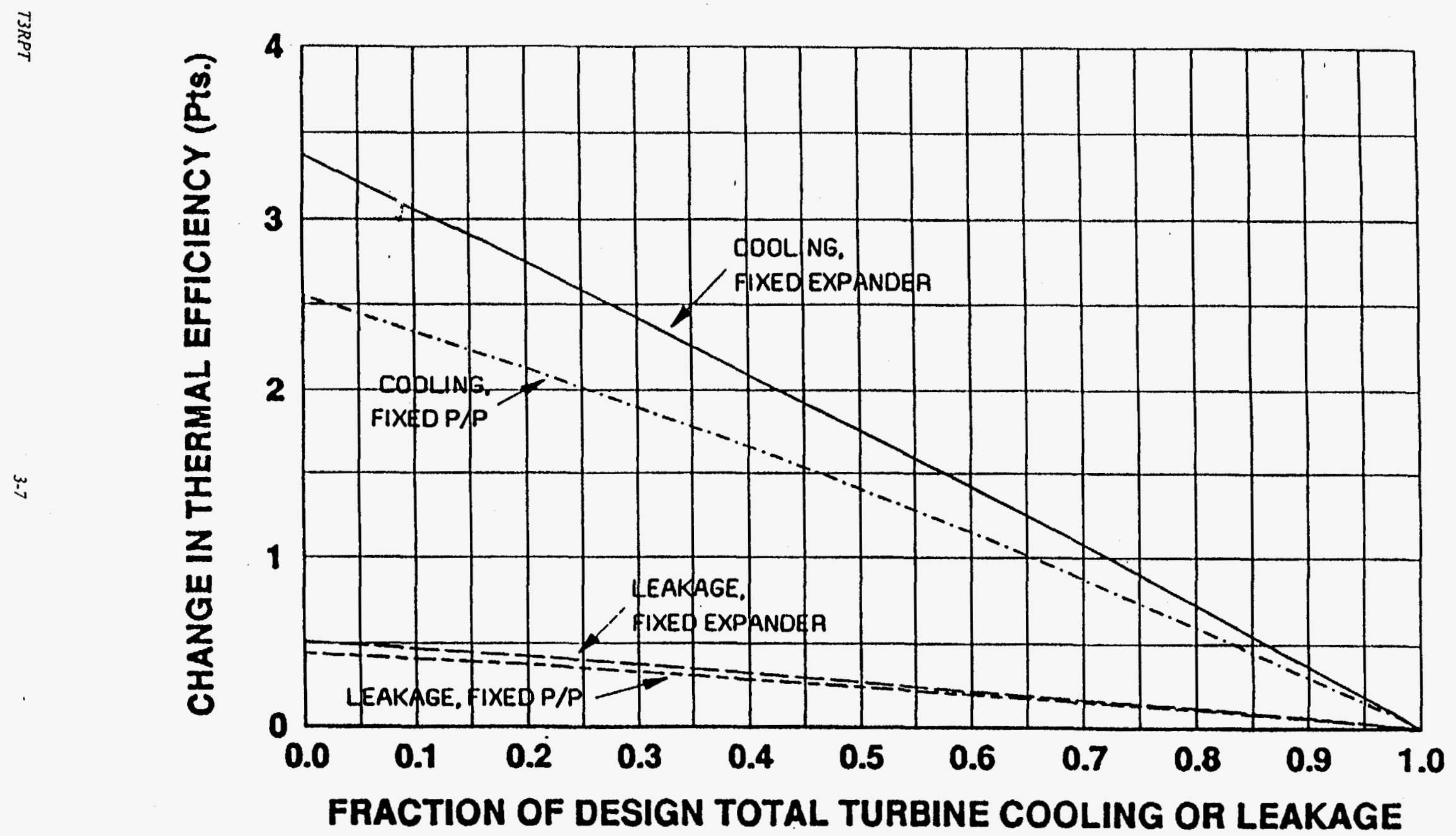

Figure 3-3. Turbine Cooling and Leakage, Effect on Combined Cycle Thermal Efficiency 
closed-loop steam cooling to the baseline configuration yields a 2 percentage point increase in combined cycle efficiency.

Closed-loop steam cooling of the transitions, which will be used on the ATS engine, will result in a small (about .05 percentage point) penalty in cycle efficiency due to heat extraction from the combustion gases. However, both closed-loop exhaust gas cooling and impingement air cooling of the transitions will result in a higher loss in cycle efficiency. The closed-loop exhaust gas cooling will be less efficient because of the work of compression. The impingement air cooling will be less efficient because of the higher combustor pressure loss requirement for this type of transition cooling scheme.

\section{INCREASED COMPRESSOR PRESSURE RATIO}

Commercial aircraft gas turbine engines are designed with high overall pressure ratios, to maximize the simple cycle efficiency. For the ideal Brayton gas turbine cycle, the cycle efficiency is a function solely of the cycle pressure ratio and increases with cycle pressure ratio. In real cycles, the effect of non-ideal components causes the peak efficiency pressure ratio to decrease significantly from that of the Brayton cycle. Figure 3-4 shows the effect of compressor pressure ratio on simple cycle performance for a family of engines based on the high temperature combustion turbine of the baseline configuration. Also included in Figure 3-4 are the corresponding steam cycle and combined cycle efficiencies. Note that the simple cycle efficiency curve is relatively flat above a pressure ratio of approximately 40 . This indicates that it is nearing the peak simple cycle efficiency. The steam cycle efficiency is seen to decrease with increasing combustion turbine pressure ratio. This is due to the reduction in combustion turbine exhaust temperature, which in turn reduces the maximum steam temperature and pressure and the steam's availability, and results in lower steam cycle efficiency. The effect of all of this on combined cycle efficiency is that it peaks around a pressure ratio of about 20 , but remains approximately constant for a relatively large increase in compressor pressure ratio.

Reducing the compressor pressure ratio below the baseline value of 18 results in a significant decrease in combined cycle efficiency. This is due to the fact that, since the maximum steam temperature considered for this study was $1100^{\circ} \mathrm{F}$, any decrease in pressure ratio below the baseline value of 18 , where the maximum steam temperatures are reached, will increase the turbine exhaust temperature while maintaining the steam temperatures at $1100^{\circ} \mathrm{F}$. This results in a much smaller increase in steam cycle efficiency than that obtainable by allowing the steam temperatures to rise with the turbine exhaust temperature. Figure 3-4 shows the significant reduction in the slope of the steam cycle efficiency line at this point, which causes the combined cycle efficiency decrease.

The maximum work output of the Brayton cycle occurs at a significantly lower value of pressure ratio than that for the peak efficiency. Figure 3-5, which includes intercooled cycle characteristics to be discussed later, shows the specific output of the cycles in Figure 3-4 (solid lines). The simple cycle peak specific output occurs at a pressure ratio 


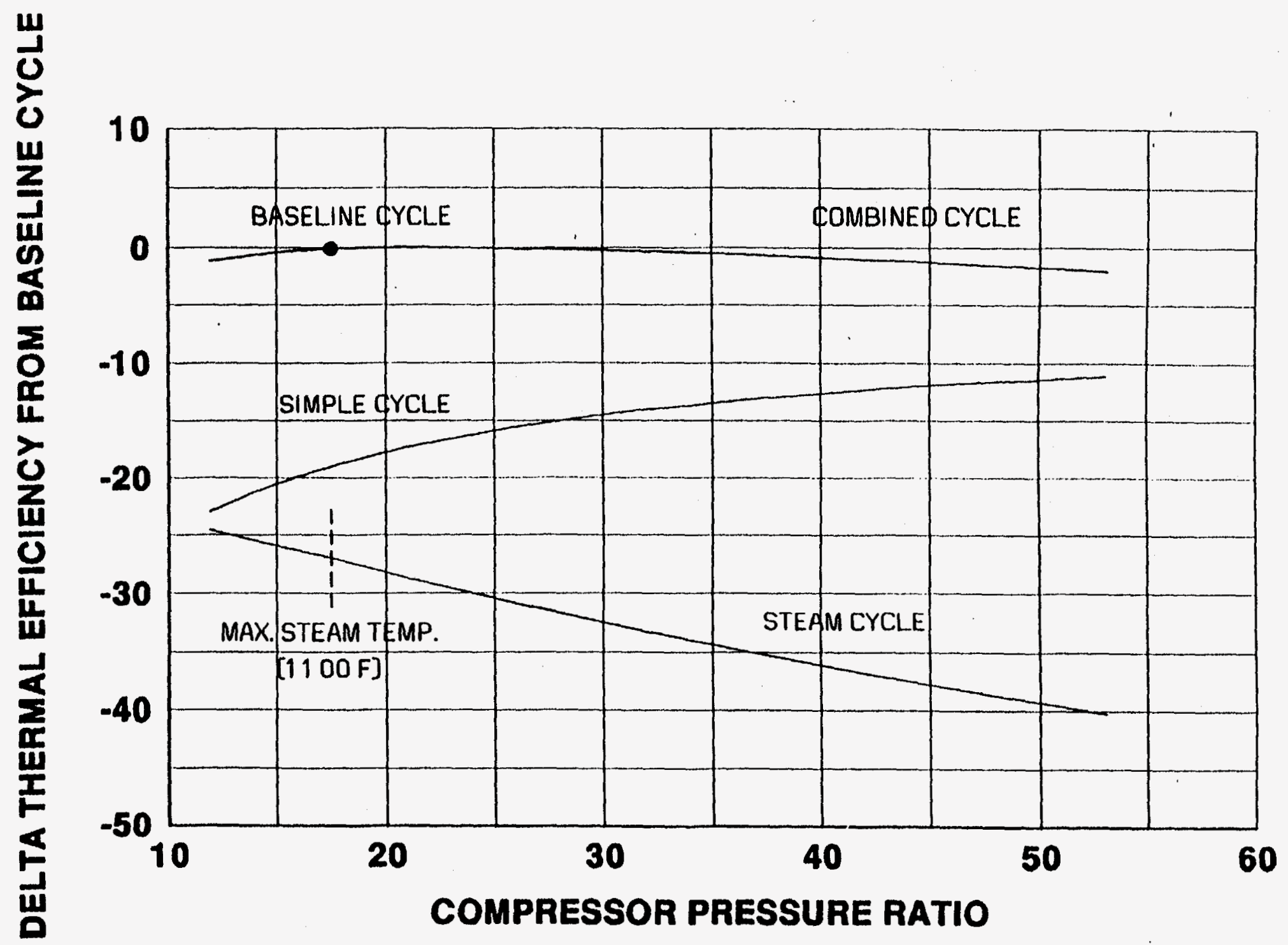

Figure 3-4. Compressor Pressure Ratio, Effect on Thermal Efficiencies 


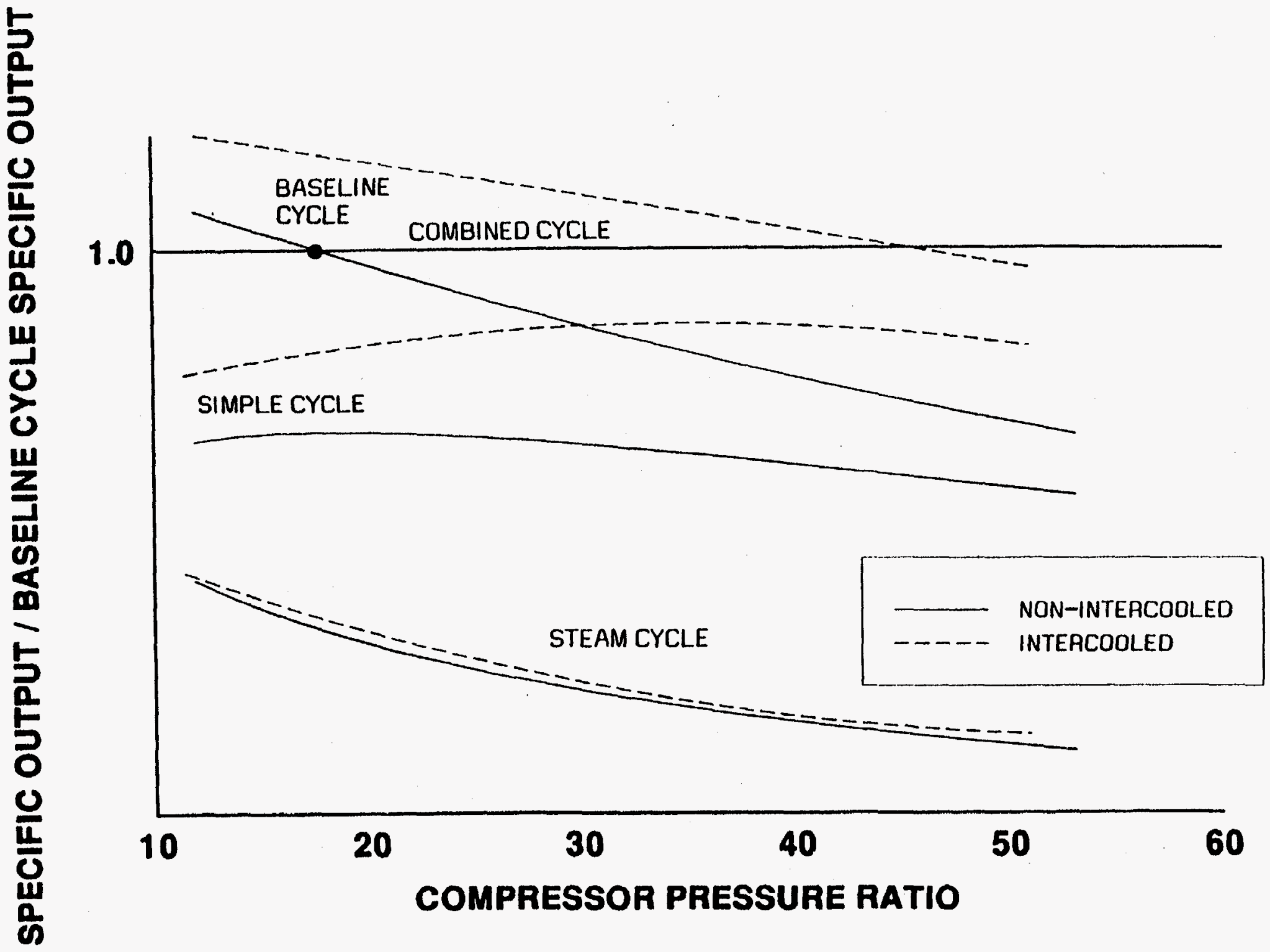

Figure 3-5. Compressor Intercooling, Effect on Specific Output 
of approximately 18. Also, note that the steam cycle specific output is reduced as pressure ratio is increased, since there is less exhaust energy available to the steam cycle. The combined cycle specific output, which is merely the sum of the simple cycle and steam cycle specific outputs, decreases for increasing pressure ratio across the entire range shown.

Therefore, to select the lowest pressure ratio at which the peak combined cycle efficiency level is obtained should be the design point. In this way both efficiency and output are maximized, and the cost of electricity is minimized (the high temperature engine baseline cycle is designed in this fashion).

The results of the above analysis apply to air cooled combustion turbines. To determine the optimum pressure ratio for closed-loop steam cooled turbines, the effects of the closed-loop steam cooling must first be considered. Since the turbine gas path temperature is reduced far less for closed-loop steam cooling than for air cooling, the combustion turbine exhaust temperature is higher for closed-loop steam cooled turbines than air cooled turbines operating at the same pressure ratio. Application of closed-loop steam cooling to the baseline configuration results in an increase in turbine exhaust temperature of approximately $100^{\circ} \mathrm{F}$. Therefore, since Figure 3-4 indicates that cycle pressure ratio should be set so that turbine exhaust temperature is equal to the maximum steam temperature plus margin for the superheater approach, cycle pressure ratio must be increased to reduce the turbine exhaust temperature $100^{\circ} \mathrm{F}$. In the baseline cycle, this corresponds to increasing cycle pressure ratio from 18 to 25 . Note that the steam cycle will still have the same efficiency as the optimum steam cycle, but the combustion turbine simple cycle efficiency has been increased by approximately 3 percentage points (see Figure 3-4). This results in a further increase in combined cycle efficiency of 1.6 percentage points, bringing the total combined cycle efficiency increase due to application of closed-loop steam cooling to 3.6 percentage points.

\section{INCREASED TURBINE INLET TEMPERATURE}

Since thermal efficiency increases with increasing turbine inlet temperature, the potential benefits of increased turbine inlet temperature were investigated. The RIT for the high temperature engine baseline cycle was increased $300^{\circ} \mathrm{F}$ to $2900^{\circ} \mathrm{F}$. This resulted in a cycle output increase of $10 \%$, and combined cycle thermal efficiency increase of slightly more than 1 percentage point. The reason that the performance increase was relatively small for such a large increase in turbine rotor inlet temperature is that, since the cooling technology remained constant as the temperature was increased, large amounts of additional turbine cooling air were required to maintain turbine material operating temperatures at acceptable levels. This increase in cooling flow decreased cycle efficiency by the three mechanisms described earlier, and this significantly offsets the benefit of increasing the turbine rotor inlet temperature. Therefore, since efficiency and output would have been increased much more if turbine cooling was held at the same level as in the baseline cycle, increased turbine operating temperature must be accompanied by corresponding advancements in turbine cooling. However, even if 
cooling technology advancements were available to allow operation at much higher rotor inlet temperatures, the formation of NOx at these higher temperatures would result in unacceptable emissions characteristics.

\section{COMPRESSOR INTERCOOLING}

The typical arrangement for compressor intercooling involves removing the compressor air flow partway through the compressor temperature rise, sending it through an air-towater heat exchanger, and then returning it to the compressor for further compression to combustor inlet pressure. The heat removed from the compressor air flow by the intercooler is rejected to the atmosphere, because, at the pressure ratios considered in this study, the heat is of too low a quality to be of use to the cycle.

Another intercooling concept is to spray water droplets into the compressor. As the air is compressed and increases in temperature, the water evaporates and absorbs heat. This results in a continuous cooling of the compressor. Note that for this concept the heat absorbed by the water is also rejected to the atmosphere, since this water is never condensed by the cycle but instead exhausted with the stack gases as low pressure steam.

Compressor intercooling reduces the compressor work, because it compresses the gas at a lower average temperature. Since the combustion and steam turbines produce approximately the same output as in the non-intercooled case, the overall cycle output is increased. However, since the compressor exit temperature is lowered, the amount of fuel that must be added to reach a given turbine inlet temperature is greater than that for the non-intercooled case. The ratio of the amount of compressor work saved to the amount of extra fuel energy added is about equal to the simple cycle efficiency. It can therefore be concluded that intercooling adds output at approximately the simple cycle efficiency. Since combined cycle efficiencies are significantly greater than simple cycle efficiencies it would be expected that the additional output at simple cycle efficiency would reduce the combined cycle net plant efficiency for the intercooled case. Figure 3-6 verifies this expectation and shows that this trend is the same for a wide range of cycle pressure ratios. Note that the simple cycle shows almost no change in efficiency for intercooling, which is expected since output is added at approximately the simple cycle efficiency.

Figure 3-5 shows the effect of intercooling on specific output. Since the compressor work requirement is reduced while the gas and steam turbine work outputs remain approximately the same as in the non-intercooled case, the net power output of both the simple and combined cycles is increased. Also, since the turbine exhaust temperature is increased slightly due to the aforementioned exhaust gas composition effects, the steam cycle specific output is also increased slightly.

\section{RECUPERATION}

In recuperative cycles, turbine exhaust heat is recovered and returned to the combustion turbine combustor, usually via a heat exchange between the turbine exhaust gases and the 
DELTA THERMAL EFFICIENCY FROM BASELINE CYCLE

을

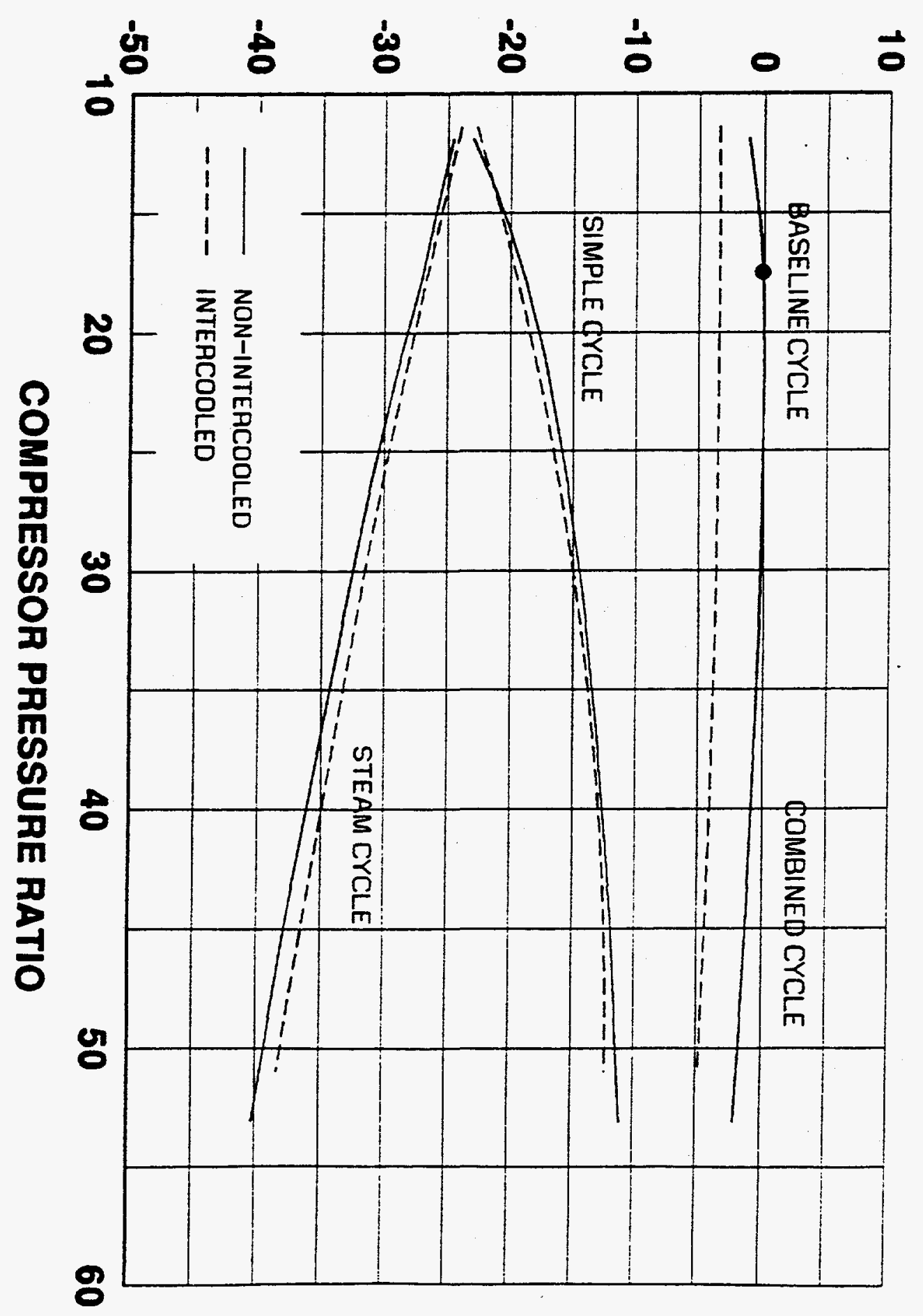


compressor exit air flow. The discharge from the compressor exit is piped to an exhaust gas-to-air heat exchanger located aft of the combustion turbine. It is then heated by the turbine exhaust and returned to the combustor. Since the resulting combustor air inlet temperature is increased above that of the non-recuperated cycle, less fuel is required to heat the air to a given turbine inlet temperature. Because the turbine work and the compressor work are approximately the same as in the non-recuperated cycle, the decrease in fuel flow results in an increase in thermal efficiency. This is especially true for the simple cycle, since the heat recovered by recuperation is rejected to the atmosphere in the non-recuperative case. For combined cycles the efficiency is also increased, because the combustion turbine recovers the recuperated heat at the simple cycle efficiency, which is larger than the 30 to $35 \%$ thermal efficiency of the bottoming steam cycle, which recovers this heat in the non-recuperated case.

Installation of a recuperation system on the baseline configuration results in an increase in thermal efficiency of 1 percentage point. The steam cycle in this recuperated cycle has a lower efficiency than the steam cycle in the baseline configuration, because the recuperator exit temperature is significantly lower than the turbine exhaust temperature. However, the effect of reduced steam cycle efficiency is smaller than the effect of recovering the recuperated heat at the combustion turbine efficiency.

Since the combustor inlet flow is smaller than the turbine exhaust flow (due to the removal of the turbine cooling air prior to combustion) and has a higher specific heat (due to the combustion of the fuel), the heat capacity of the turbine exhaust flow is somewhat higher than that for the burner inlet flow. This means that the recuperated cycle described above does not fully utilize the quantity of heat available in the turbine exhaust. By placing a steam superheater in parallel with the recuperator, the remainder of the available turbine exhaust heat can be recovered at its maximum quality. The maximum steam temperature can then be raised to that of the baseline cycle $\left(1000^{\circ} \mathrm{F}\right)$, and the cycle efficiency is increased by an additional 0.1 percentage point.

Since recuperative cycles return exhaust energy to the combustion turbine, less energy is available to the steam cycle, and the resulting steam turbine output is lower than that of the baseline configuration. However, the combustion turbine output is approximately the same as in the baseline cycle (minus losses in the recuperation system). This means that recuperative cycles carry a significant output penalty, with this penalty being proportional to the amount of recuperation performed.

\section{INTERCOOLING WITH RECUPERATION}

For a simple cycle, the combination of intercooling with recuperation eliminates the problem of the reduced combustor inlet temperature associated with intercooled cycles. The simple cycle then gets the benefit of the reduced compressor work and, at all but high pressure ratios, actually has a higher burner inlet temperature than the corresponding nonintercooled, non-recuperated cycle. This results in a dramatic increase in the simple cycle efficiency. 
However, the bottoming cycle receives even less energy than in the recuperated cycle, since the recuperator removes much more heat from the turbine exhaust than in the recuperated, non-intercooled cycle. The additional heat removed corresponds to the heat rejected to the atmosphere by the intercooler. This means that we have merely displaced the lost energy of the intercooler by taking energy from the bottoming cycle. This is in addition to the energy already removed from the bottoming cycle in the non-intercooled, recuperative cycle. This results in a very low recuperator exit temperature, which in turn translates into a low generated steam pressure (low availability) and a low efficiency steam bottoming cycle. The result is that, while simple cycle efficiency can be increased to over $50 \%$, the combined cycle efficiency is reduced for the entire useful range of compressor pressure ratios. For conventional air-to-water heat exchanger intercooling of the compressor, the combined cycle efficiency is reduced approximately 1.9 percentage points at the baseline cycle pressure ratio. For continuously cooled compressors utilizing water droplet spraying into the compressor, the combined cycle efficiency is reduced by 0.4 percentage point.

Since the continuously cooled compressor with recuperation is not far below the baseline level of combined cycle thermal efficiency, it is worth investigating further optimization of the steam cycle in this case. As mentioned earlier, steam may be superheated in parallel with the recuperator, yielding more efficient recovery of the heat available to the steam cycle. Utilizing this approach, along with a two pressure level steam cycle, results in an increase in net plant efficiency of 0.8 percentage point over the baseline efficiency level.

Another approach to optimizing the intercooled recuperative cycle is to place a saturator between the compressor exit and the recuperator entrance, as illustrated in the combined cycle shown in Figure 3-7. This saturator, also called an aftercooler, evaporates water into the compressor exit flow, resulting in a lower temperature, higher mass flow entering the recuperator. While this may be seen as a way to better balance the heat capacities of the hot and cold streams in the recuperator and thereby increase the amount of heat recuperated by the combustion turbine (in addition to the fact that the air flow is at lower temperature), it is important to realize that all of this additional recuperation is accomplished by the evaporation of water in the saturator. Since this water is never condensed by the cycle but instead is rejected through the stack as low pressure steam, the additional amount of energy recuperated is not recovered anywhere in the cycle. Furthermore, the recuperator exit temperature is reduced even further than in the intercooled recuperative cycle, resulting in an even lower efficiency steam cycle. Finally, note that, since the heat capacity of the cold side recuperator flow now closely matches that of the hot side flow, parallel steam superheat cannot be utilized to increase the steam cycle efficiency. The application of this concept to the baseline cycle results in a decrease in thermal efficiency of 2 percentage points. 


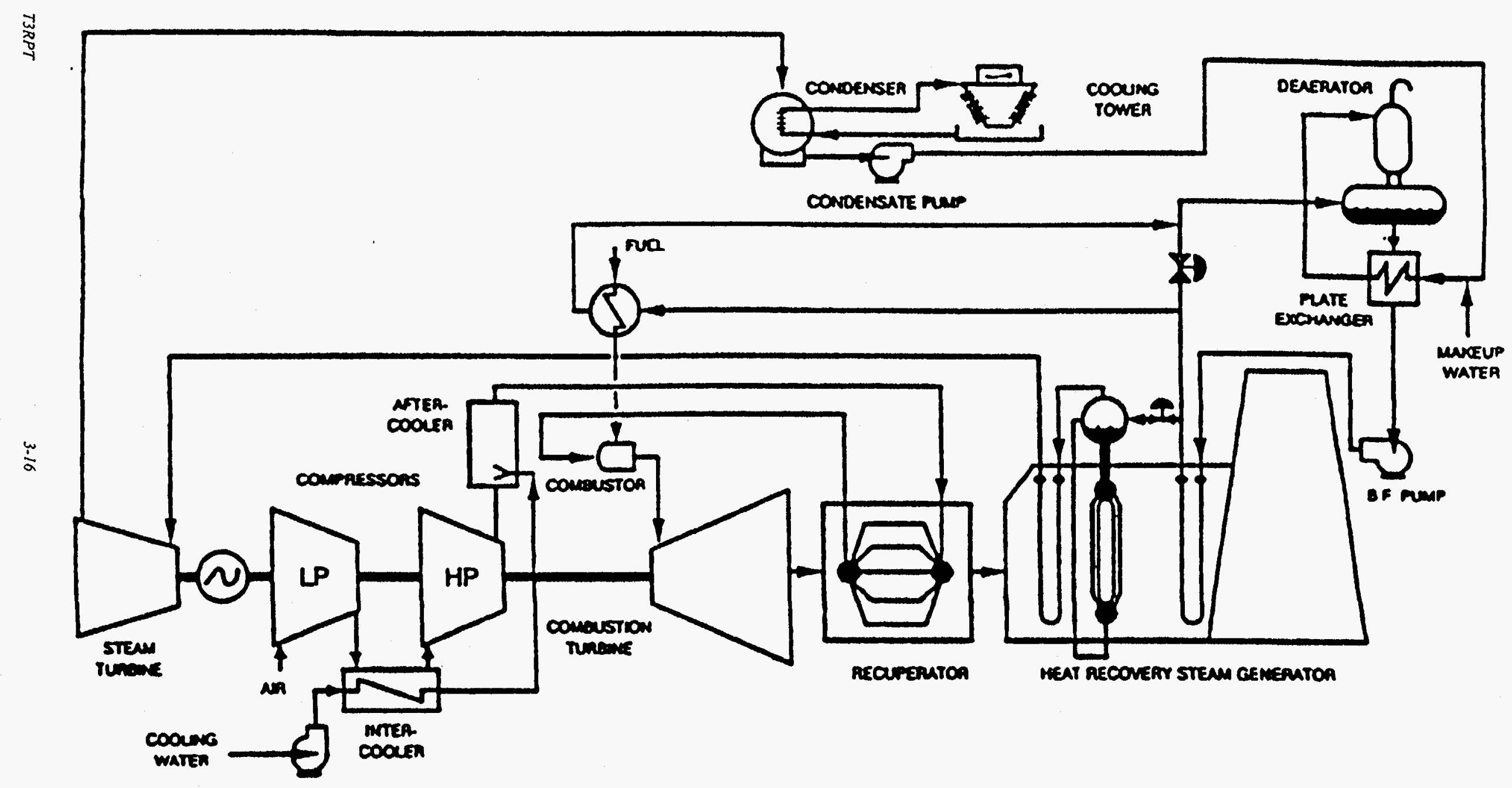

Figure 3-7. Intercooled, Aftercooled (Evaporative), Recuperative Combined Cycle 


\section{REHEAT COMBUSTION TURBINE}

Reheat combustion turbines utilize a two step combustion process in which the air is compressed, combusted, expanded in a turbine to some pressure significantly greater than ambient, combusted again in a second combustor, and finally expanded by a second turbine to near ambient pressure. For a fixed turbine rotor inlet temperature limit, the simple cycle efficiency is increased for a reheat combustion turbine compared to a nonreheat cycle operating at a pressure ratio corresponding to the second combustor's operating pressure. This is because the reheat cycle performs some of its combustion and expansion at a higher pressure ratio, which increases simple cycle efficiency (see section on increased compressor pressure ratio). From a purely thermodynamic standpoint, the average temperature at which heat is added is raised, thus raising the Carnot efficiency of the cycle. For combined cycles the turbine exhaust temperature can be controlled by the selection of second turbine inlet temperature and expansion ratio. This in turn allows control over the efficiency of the steam bottoming cycle.

Another beneficial feature of reheat combustion turbine cycles is that they exhibit higher output for a fixed compressor flow rate and turbine inlet temperature than non-reheat cycles. This is due to the fact that they burn sequentially with an expansion between the combustors. This allows for the addition of more fuel (in the second combustor) without violation of the turbine rotor inlet temperature limit. Also, since this results in a higher fuel-to-air ratio than in non-reheat cycles, they burn closer to stoichiometry and exhaust lower concentrations of excess oxygen.

Applying combustion turbine reheat to the baseline cycle, with the second combustor operating at the exit pressure and temperature equal to those of the baseline cycle, results in nearly identical turbine exhaust temperatures, and therefore the steam cycle of the combustion turbine reheat case is not compromised and is identical to the steam cycle of the baseline cycle. However, the compressor pressure ratio has been increased to 36 . This necessitates the addition of 6 compressor stages, and an additional combustor and turbine stage located upstream of the second combustor. The simple cycle efficiency is increased nearly 2 percentage points from the baseline simple cycle level. Since steam cycle efficiency remains at the level of that in the baseline cycle, the combined cycle efficiency is increased 1.3 percentage points.

An investigation was made into the application of intercooling and recuperation to reheat combustion turbine cycles with the same, reduced efficiency results as for non-reheat combined cycles.

\section{THERMOCHEMICAL RECUPERATION}

In a thermochemical recuperation power plant, a portion of the stack exhaust (flue) gas is removed from the stack, compressed, mixed with natural gas fuel, heated with exhaust heat from the combustion turbine, and mixed with the compressor exit air as it enters the combustor. As the mixture of natural gas and flue gas is heated by the combustion 
turbine exhaust, an endothermic reaction occurs between the methane and the carbon dioxide and water in the flue gas. This reaction occurs in the presence of a nickel-based catalyst, and results in the production of hydrogen and carbon monoxide. For complete conversion of the methane, the effective fuel heating value is increased approximately $30 \%$. Therefore, the natural gas / flue gas mixture absorbs heat thermally (as it is heated) and chemically (via the endothermic reaction), resulting in a larger potential recuperation of exhaust energy than could be obtained by conventional recuperation, which recovers energy by heat alone. In fact, with full conversion of the natural gas fuel to hydrogen and carbon monoxide, up to twice the energy recuperated by the standard recuperative cycle may be recovered.

The endothermic reaction described above is accelerated for low excess oxygen in the reacting mixture, low pressures, and high mass ratios of recirculated flue gases to methane. Therefore, in order to take full advantage of this concept, the engine is controlled by running the combustor at near stoichiometric fuel-to-air ratios $(10 \%$ excess air at the combustor exit) and using flue gas recirculation to quench the combustion products down to the desired turbine inlet temperature. This maximizes flue gas recirculation and minimizes excess oxygen in the flue gas. For typical cycles utilizing this control philosophy, the resulting recirculation rate of flue gas is over $50 \%$ of turbine flow. This means that both the air compressor flow rate and stack exhaust flow rate are less than half that of conventional cycles with the same turbine size.

Another advantage of the thermochemical recuperation / flue gas recirculation (TCR/FGR) concept is that, because the fuel has a low adiabatic flame temperature, it contains a significant amount of hydrogen and operates with very low levels of excess oxygen in the exhaust, the resulting emissions of $\mathrm{NOx}$ and $\mathrm{CO}$ are much lower than those for conventional design power plants.

When applied to the baseline configuration, thermochemical recuperation yields a combined cycle thermal efficiency over 2 percentage points greater than that of the baseline cycle for several different TCR/FGR configurations. There are many possible cycle configurations, other than those described above, which can utilize thermochemical recuperation. One of these, using steam reforming, is illustrated in Figure 3-8.

\section{STEAM INJECTION}

To apply steam injection to the baseline configuration, both the high pressure and low pressure steam systems are eliminated, leaving only the intermediate pressure steam system. The intermediate pressure superheated steam is then routed into the combustion turbine combustor inlet. Therefore, all steam turbines are eliminated, along with the condenser and the cooling tower. This results in a cycle which is significantly less expensive to build than the baseline cycle and it provides a means to reduce NOx emissions via the large amount of steam injection. However, the cost associated with demineralization of the large cycle make up flow must also be considered. 


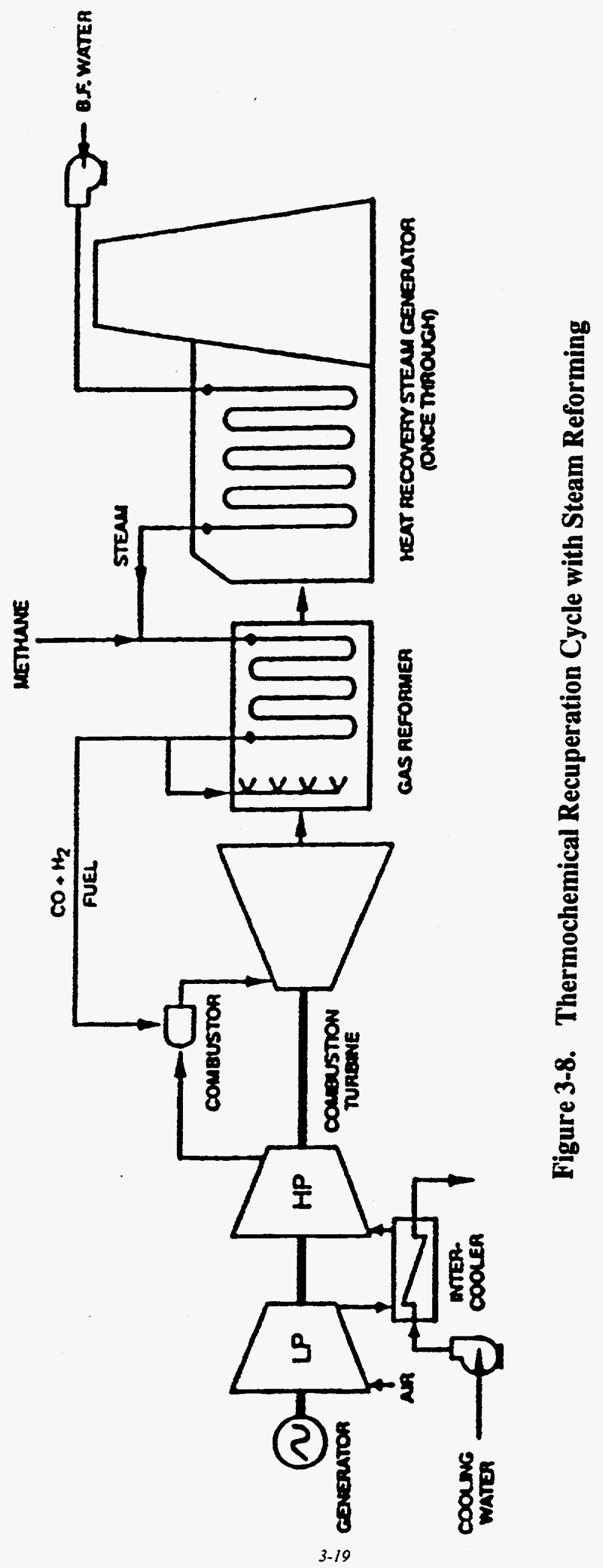


For a given turbine flow area, the compressor flow size must be reduced significantly, due to the addition of a large amount of steam, which now must pass through the turbine in addition to the compressor exit air flow. Since the steam is generated with exhaust heat, which is not used in a simple combustion turbine cycle, this concept provides a significant portion of the combustor inlet gas flow with very little work requirement (a small amount of energy is needed to run the feedwater pumps which pump the water to the intermediate steam pressure). Therefore, from a simple cycle standpoint, the work of compression is much reduced due to the fact that some of the combustor inlet gas flow is compressed as a liquid. Also, the turbine output is increased significantly, since the average specific heat of the working fluid is increased considerably by the presence of the steam. The simple cycle efficiency and output are therefore increased by steam injection.

Compared to combined cycles, however, elimination of the high pressure steam system results in generation of more intermediate pressure steam, but this steam is at significantly lower availability due to its lower pressure. Also, since the low pressure steam system has been eliminated as well, the exhaust stack gas temperature is much higher, as is the associated heat loss. Finally, since the steam injected into the gas turbine is effectively throttled to its partial pressure upon mixing with the compressor exit air without doing any work, and is only expanded to its partial pressure in the exhaust stack (which is significantly higher than typical low pressure steam turbine exit pressure), the resulting steam expansion ratio is much smaller than that of the conventional steam turbine cycle. These losses result in a reduction in combined cycle efficiency in the range of 5 to 8 percentage points. Net plant output, while much higher than the baseline configuration simple cycle output, is less than the combined cycle output. 


\section{Section 4}

\section{EVALUATION OF CANDIDATE SYSTEMS}

Seven natural gas-fired combustion turbine power plants were selected to be evaluated using Version 6 of the Electric Power Research Institute (EPRI) Technical Assessment Guide (TAG). A RAM analysis was also performed for each plant configuration.

Westinghouse, Gilbert/Commonwealth (G/C) and EPRI data bases were used to estimate the cost of advanced and commercially available systems. The EPRI TAG was then used to calculate the levelized Cost of Electricity (COE) for each plant. The levelized COE is a sum of five levelized components (i.e., carrying charges [a function of capital cost], fixed and variable operating and maintenance expense, variable operating and maintenance expense, cost of consumables, and fuel costs).

The following assumptions were made for all seven plant configurations:

\section{Location - Ohio River Valley}

Capital Cost Year Dollars - 1994 (January)

Delivered Cost of Natural Gas - \$3.00/MBtu

Land Area/Unit Cost - 12.5 acre (\$8,000/acre)

Project Book Life - 30 years

Project Tax Life - 20 years

Tax Depreciation Method - Reform

Property Tax Rate - 1.0\%/year

Insurance Tax Rate - $1.0 \%$ year

Federal Income Tax Rate - 34.0\%

State Income Tax Rate - 6.0\%

Weighted Cost of Capital - 10.8\%

General Escalation - 4.0\%/year

Fuel Price Escalation - 6.5\%/year

For the seven natural gas-fired combustion turbine cycles evaluated, a capacity factor of $90 \%$ was assumed. The plant configuration designated ATS with a 25:1 pressure ratio was selected as the best economical choice that also has a plant RAM (92\%) equivalent to today's commercial practice. (The combustion turbine RAM for ATS is $95 \%$ which again matches today's commercial practice.)

This ATS plant was compared against the Reference Plant (a combined cycle which uses a Westinghouse $501 \mathrm{~F}$ combustion turbine), a new high temperature combustion turbine with a standard Rankine cycle, a new high temperature combustion turbine with an improved Rankine cycle, an ATS plant with a (35:1) pressure ratio, a recuperative cycle, and a reheat combustion turbine cycle. The calculated levelized COE for the selected 
ATS plant is $52.25 \$ / \mathrm{MWh}(5.23$ cents $/ \mathrm{kWh})$ versus $60.36 \$ \mathrm{MWh})$ for the Reference Plant, a $13.4 \%$ reduction in $\mathrm{COE}$.

Evaluation showed that the ATS plant had the lowest COE. Comparisons were also made, separately, which showed how the capital and plant efficiency can vary and still maintain a $10 \%$ COE margin. For example, the capital cost for ATS could increase $13 \%$, but the COE for ATS would still be $10 \%$, less than the Reference Plant. For the recuperative cycle a $10 \%$ decrease in capital cost is required to lower the COE margin from $6.7 \%$ to $10.0 \%$.

For additional information on the procedures used to calculate the COE and the RAM, consult Appendices A and B, respectively. 


\section{Section 5}

\section{HIGH TEMPERATURE DEVELOPMENTS}

Materials and related manufacturing technologies play a critical role in achieving the efficiency goals of the ATS program. Theoretically, there are two approaches to increase the turbine efficiency. In the first approach, the efficiency can be increased partly by improving cooling technology, thus using less cooling air to achieve the same amount of temperature reduction required to maintain the component temperatures within the capability of the materials. However, increasing cooling efficiency alone is not sufficient. The second approach is to utilize materials that have higher temperature capabilities, so that components can operate reliably at higher temperatures with reduced cooling air usage. It is only by the contribution of improved cooling technology and advanced materials combined that maximum efficiency increase can be realized. Materials with higher temperature capabilities and advanced cooling provisions will be key contributors toward meeting the ATS efficiency goals.

The high performance $501 \mathrm{G}$ engine, recently introduced at the 1994 ASME Gas Turbine Show at the Hague in the Netherlands, can claim part of its heritage from the ATS program. Specifically, the $501 \mathrm{G}$ engine will incorporate:

- Thermal barrier coatings with improved reliability

- Directionally solidified airfoils

- Enhanced airfoil cooling design

- Reduced leakage (brush seals)

\section{GENERAL MATERIALS REQUIREMENTS}

Hot section components for land based turbines typically require materials with superior mechanical properties and good corrosion/oxidation resistance at elevated temperatures. Conventional Ni- and Co-based superalloys, which are extensively used in the current land based turbines, will be considered. In addition, the protection of hot section components by oxidation/corrosion resistant coatings and thermal barrier coatings (TBC) has become a necessity.

Advanced materials, such as single crystal (SC) and direction solidification (DS) alloys, which have been developed for aeroderivative engines with proven service experience, will be evaluated for large land-based turbine applications. Furthermore, the higher firing temperature of ATS warrants the evaluation of emerging materials, such as ceramic materials and intermetallic materials. These materials have emerged from their development stage to become viable engineering materials ready to be evaluated for implementation in land-based turbines. Understandably, the development risk associated with these relatively new materials will be higher than that of the metallic alternatives. But, the potential benefits offered by these emerging materials in efficiency improvement and emission reduction are commensurably compelling. Therefore, Westinghouse 
intends to take advantage of the high temperature capabilities of these two emerging materials and evaluate them for implementation in the ATS turbine. More detailed analysis and the rationale for the material selection for the major components are discussed in the following paragraphs.

\section{Gas Turbine Disc Materials}

Turbine disc materials are critical, because they are subjected to high centrifugal stresses resulting from the load applied by the blades which are attached to the rim. The requirements for the disc materials include strength, ductility, toughness, resistance to embrittlement, and resistance to corrosion.

High strength, low alloy steels are common for disc applications in the land based turbine industry, although nickel-based superalloys, such as $\mathrm{IN}-706$, have been used by some manufacturers in recent turbine designs. High strength, low alloy steel discs are used in the turbine section of the Westinghouse $501 \mathrm{~F}$ turbine, which has a rotor inlet temperature of about $2300^{\circ} \mathrm{F}$, through the use of the cooling air to minimize in-service temper embrittlement and to assure long-term reliability of these discs.

Superalloys have superior strength at elevated temperatures compared to low alloy steels. Therefore, they can be used at higher service temperatures with reduced or eliminated cooling air, thus allowing improved turbine efficiency. Candidate disc materials under consideration are Discalloy (an iron-based superalloy similar to A286), IN-901, IN-706, $\mathrm{IN}-718$, Waspalloy, and Udimet 729. The last three materials are difficult to forge in large discs, using state-of-the-art forging and melting technologies, without producing segregation and/or casting defects. Such characteristics would adversely affect the reliability and service life of the discs. In the 1970s, Westinghouse evaluated Discalloy, IN-901, and IN-706 alloys for disc applications. Large forgings could be made with these alloys. Discalloy is less expensive compared to the latter two alloys, since it is an ironbased alloy, whereas $\mathrm{N}-901$ and $\mathrm{IN}-706$ are nickel-based alloys. Large Discalloy discs have been implemented successfully in the Westinghouse 101, 191, and 301 gas turbines, and accumulating extensive field experience. During the mid-1980's, Westinghouse in collaboration with a forging supplier, successfully produced a full size IN 706 rotor forging for the EPRI sponsored Superconducting Generator Program. Welding and machining techniques for IN 706 were also developed in this program for the fabrication of the large rotor assembly.

Low alloy steels will be considered for ATS turbine discs because of their low cost and extensive design and manufacturing experience developed in the past decades. However, with the increased RIT in the ATS there is a strong possibility that the disc temperature may increase to a level which would exceed the strength capability of low alloy steels. In that case, superalloys will be needed in order to meet the more demanding ATS disc design requirement. Upon the completion of a detailed design analysis, a superalloy material will be selected, design data generated and forging and other necessary manufacturing processes developed during Phase III of the program. 


\section{Combustion System}

The combustion system components include baskets and transitions. Inside a basket, fuel and air are mixed and burned to produce hot gases. The hot gases are then directed through a transition toward the first stage vanes. Due to their static condition, the baskets and transitions are subjected to low stresses. The key material requirements for these components are creep strength, LCF strength, corrosion/oxidation resistance, thermal fatigue resistance and ease of fabrication.

Sheet metal Ni- and Co-based alloys are the most common choice of materials for these applications by turbine manufacturers. These alloys include Hastelloy X, IN-617, Haynes 230 , Nimonic 75 , Nimonic 86 and Haynes 188 . Westinghouse has satisfactory experience using Ni-based superalloys in the baskets and transitions. However, with the recent increase in firing temperatures, in the latest turbine models, the use of TBC coatings has become mandatory to avoid distress due to excessive steady-state and transient temperatures. For the ATS combustor basket and transition applications, the current Ni-based alloys with corrosion/oxidation coatings and TBC coating will be considered as the baseline design.

However, with the latest advancement in ceramic processing technology the combustors and transitions appear to be ideal for ceramic application because of its chemical stability at high temperatures. Modern monolithic ceramic materials provide higher strength, better creep resistance and far better reliability than those of a few years ago. The addition of high strength continuous ceramic fibers woven into a two or three dimensional preform in a ceramic matrix makes the composite system even tougher and more strain tolerant than monolithic ceramics. These ceramic matrix composites (CMCs) are already in use in military aircraft engines as afterburner flame holders and exhaust nozzles. Experience gained through the development of these components has resulted in the improvement of materials, design and manufacturing methods. Westinghouse intends to build upon this existing industrial experience in the development of ceramic ATS components.

The use of ceramic materials will benefit ATS in two important areas- increasing efficiency through less cooling medium usage, and, reducing NOx emissions due to more uniform combustor temperature distributions. Therefore, the design of combustors and transitions with ceramic materials will be pursued as a more favorable option, although the risk will be higher than that of the metallic counterpart. A design of ATS ring segments with ceramic matrix composites is currently in progress under, Task 8.7. A two layer ceramic laminate will be evaluated, having an outer structural layer and an inner, thermally insulating layer. The program is expected to be completed in 1995. The experience gained from this task will certainly serve as a "stepping-stone" toward the design of the larger and more complex ceramic combustors and transitions. 


\section{Gas Turbine Vane Materials}

Turbine vanes primarily serve the function of directing the flow of hot gasses towards rotating blades. Due to their static nature, the design requirements imposed on the vanes are not as stringent as on the rotating blades. However, the vanes are subjected to gas temperatures higher than the rotating blades in the same row. Therefore, resistance to corrosion/oxidation, creep, low cycle fatigue (LCF) and thermal fatigue are the most desired properties for vane alloys. Weldability, both for fabrication and repair, is also an important factor.

The land based turbine vanes are typically made of Ni-based or Co-based alloys using a conventional casting process (CC). DS vanes will be used in Westinghouse's new $501 \mathrm{G}$ model engine, where the use of SC vanes has not yet been introduced in land based turbines. In general, Co-based alloys exhibit superior weldability and hot corrosion resistance due to their higher $\mathrm{Cr}$ contents. Westinghouse has been using Co-based alloys, such as X-45, since the mid-1960s, and has switched to a Westinghouse patented alloy, ECY -768 , since the 1970 s. ECY-768 is a Co-Cr-Ni-W alloy, which exhibits significantly higher creep strength than $X-45$. In order to improve the low cycle fatigue strength of ECY-768, Westinghouse has recently optimized its carbon content, and the resulting alloy was WES-100. WES- 100 vanes are now standard in the Westinghouse $501 \mathrm{~F}$ engines. Co-based alloys, such as ECY-768 and WES-100, in combination with more efficient cooling schemes and the use of oxidation/corrosion coatings and thermal barrier coatings, will be considered for the ATS vane application.

In addition to the Co-based alloys, Ni-based alloys need to be considered. Ni-based alloys in general are inferior to Co-based alloys in hot corrosion resistance, and they are more difficult to weld. However, Ni-based alloys have stronger creep strength than Cobased alloys in the CC condition. Furthermore, Ni-based alloys can be cast in the DS condition, which typically shows 5 to 8 times improvement in LCF life and also an increase in creep temperature capability as compared to the corresponding alloys in the CC condition. Co-based alloys are not used in the DS condition. IN-939 and IN-738 alloys, which contain high $\mathrm{Cr}$ for corrosion resistance and are widely used by European turbine manufacturers, will be considered for use in these vanes. CM247LC in DS condition will also be considered. Due to the higher firing temperatures of the ATS, the hotter stages, Rows 1 and 2 for example, may require the creep and LCF strengths of the DS Ni-based alloys. These alloys can be cast in the DS condition to further enhance the creep and LCF properties of the vanes, if needed. Because of the high temperature environment, all vanes will be coated with corrosion/oxidation resistant coatings and thermal barrier coatings.

The selection of vane materials from the above Co-based and Ni-based alloys, and the CC versus DS casting conditions, will largely depend on the cooling scheme and the corresponding stress and temperature requirements of each individual row of vanes. Preliminary design analysis appeared to favor $\mathrm{Ni}$-base alloys which contain high $\mathrm{Cr}$, such as IN 939, due to their high strength and desirable corrosion resistance. However, its 
chemistry may need to be modified in a Phase III development program to enhance its weldability for the ATS vane application.

\section{Turbine Blade Materials}

Based on the latest design stress analysis, $\mathrm{Ni}$-based superalloys are considered to be the primary candidate for rows 1 to 3 blades. The 4 blades, which are expected to be subjected to higher fatigue and creep stresses may require intermetallic materials. The analysis and rationale are presented below:

\section{Rows 1 to 3 Blade Alloys}

Turbine blades of modern land based turbines are primarily made of Ni-based superalloys, such as $\mathrm{IN}-738$ castings (cast by conventional casting process) and Udimet 520 forgings. These alloys are typically limited to the blade application up to $1650^{\circ} \mathrm{F}$ or $1700^{\circ} \mathrm{F}$ metal temperature range due to creep. Materials with higher temperature capability will be needed for the ATS. Reducing cooling air to increase efficiency requires that the blades operate at higher temperatures. Within the time frame of development of the ATS engine, the most viable candidate materials are high strength $\mathrm{Ni}$ based alloys, and alloys which can be cast with DS and SC casting processes, in combination with oxidation/corrosion resistant coatings and thermal barrier coatings.

Westinghouse has long recognized the need for high temperature blading alloys, and has been working on developing corrosion resistant DS and SC Ni-based alloys for turbine blade applications. In these development alloys, $\mathrm{Cr}$ content is maintained at a significantly higher level than that of current aeroderivative SC and DS alloys to promote corrosion resistance, which is more a concern for land based turbines than for aero engines. Preliminary test data from the DS blade development indicates that these new DS alloys offer a substantial temperature advantage over conventionally cast equiaxed IN-738. Castability studies of these alloys are in progress. The Westinghouse DS alloys are expected to have better corrosion resistance than the current commercial aeroderivative Ni-based blade alloys due to their higher $\mathrm{Cr}$ contents, but it is not certain that the creep strength would meet the ATS design requirements.

Westinghouse has been evaluating experimental SC alloys. SC slabs and bars have been cast from these alloys and the materials are being tested. The objective of this program is to develop a corrosion resistant $\mathrm{SC}$ blade material with an extra $50^{\circ} \mathrm{F}$ to $100^{\circ} \mathrm{F}$ temperature capability compared to the corresponding DS blade materials. The Westinghouse SC development program is still in the early stages of development. Therefore, to assure that materials are available to meet the schedule, it is necessary to evaluate aeroderivative SC and DS materials.

CMSX-4 SC alloy and CM247LC DS alloy have been used extensively for airfoil applications in aero engines and small industrial gas turbines, and therefore have been selected for the ATS blade development. CMSX-4 is a second generation single crystal 
superalloy containing $3 \%$ rhenium (Re). CM247LC is a derivative of the MAR-M-247 alloy, specially designed for aeroderivative DS turbine blades and vanes. These materials offer excellent creep strength, long-term stability and castability (for small airfoils), and represent the most advanced SC and DS alloys commercially available to date. CM247LC in the DS condition and CMSX-4 in the SC condition offer approximately $90^{\circ} \mathrm{F}$ and $200^{\circ} \mathrm{F}$ temperature advantages, respectively, at typical operating stress levels, as compared to the current land based blade material IN-738 in the conventional casting condition.

The industrial experience with both CM247LC DS and CMSX-4 SC alloys to date has been limited to relatively small airfoils primarily for aircraft engines or small industrial turbines. The castability of these alloys and their applicability to large size blades used in industrial power generation turbines have yet to be verified, because of concerns about grain structure control, chemical segregation and property uniformity. A castability study of CMSX-4 SC blades using 501F blade design as a prototype is now underway with a leading casting supplier. A similar castability study will be needed for the CM247LC vanes and blades. If the results of the castability studies are favorable, further work, such as heat treatment and HIP process optimization, design property data, corrosion/oxidation characterization and coating compatibility, will follow in Phase III of the ATS program to support the further design and manufacturing effort.

Even with the temperature advantages offered by the DS and SC alloys, the merit of CC alloys can never be ignored due to easier castability and lower cost. CM247LC (CC) will be evaluated for applications in the latter stages, where temperatures are lower and DS condition may not be needed. CM247LC, the low carbon version of the MAR-M-247 alloy, in the CC condition, has been used for airfoils and disks in the aeroderivative engines. Although it was originally developed for the DS processing, the lower carbon content plus other alloy modifications are also beneficial to the castability and mechanical properties of the $\mathrm{CC}$ castings. It is selected for the blade CC casting because its creep rupture strength is superior to that of the $\mathrm{CC}$ casting alloys used in the land based turbines. However, whether the alloy can be cast in the large size land based blades with intricate cooling schemes and shroud overhangs has yet to be demonstrated.

In summary, Westinghouse plans to take advantage of the existing successful experience in the aeroderivative alloys, CM247LC (in both CC and DS conditions) and CMSX-4 (SC) alloys, and evaluate them in parallel with the Westinghouse SC and DS developmental alloys for the ATS turbine applications. The CMSX-4 SC alloy offers the greatest temperature advantage, but the cost will be the highest because of the high reject rate normally associated with the SC process. The CM247LC alloy with $\mathrm{CC}$ processing offers the lowest cost option, but the relatively lower creep strength most likely will limit the use of this alloy to the cooler latter turbine stages. Understandably, the CM247LC DS alloys offer a middle ground between the SC and CC options in terms of temperature capability and cost. Since these blades will be subjected to a high temperature environment, they will be protected with corrosion/oxidation resistant coatings and TBC coatings. The final selection of alloys and casting processes will depend on the 
temperature and stress requirements corresponding to the cooling scheme at each stage. By making the CC, DS and SC options available for ATS blade design, and tailoring the cooling scheme for each individual row of blades, the optimization between component cost and system efficiency can then be achieved.

\section{$\underline{\text { Row } 4 \text { Blade Alloys }}$}

The row 4 blades in the ATS engine are expected to operate at a higher temperature than those in the $501 \mathrm{~F}$ and $501 \mathrm{G}$ engines. In addition, the ATS engine will employ larger row 4 blades in order to minimize exhaust loss and improve efficiency. Since the blade operating stress is proportioned to its length, this results in highly stressed blades. The combination of high temperature and stress therefore requires a material which exhibit higher creep and fatigue strengths than the current IN-738 material. Other conventional Ni-base superalloys, such as CM247 may not meet the creep and fatigue strength requirement either. $\mathrm{CM} 247$ in the $\mathrm{CC}$ condition offers about $50^{\circ} \mathrm{F}$ advantage in creep resistance and 15\% higher HCF strength as compared to IN738. CM247 in the DS condition does not improve the HCF strength over the CC condition. Therefore, it is necessary to develop a new material for the subject application.

Intermetallic materials offer a high strength to weight ratio which make them very attractive for high temperature rotating component application. These materials have not as yet found industrial application because they initially suffered from low ductility. However, in the last decade, significant advancement has been made in understanding these materials and overcoming the brittleness problem through the research and development work under NASP, HITEMP programs, and ORNL funded programs. Today, a number of intermetallic systems have emerged and are ready to be evaluated for implementation. Among them, Ti-Al and Ni-Al intermetallics appear to be most promising and will be considered for the ATS row 4 blade application.

\section{Coatings For Hot Section Components}

The Co- and Ni-based alloys used in the hot section components have less than desirable corrosion/oxidation resistance in the turbine environment. The reason for this is that they are primarily designed for high temperature strength, and the chemistries required for strength and corrosion/oxidation resistance are not the same. Therefore, protective surface coatings are essential for reliable and durable performance of hot gas path components. Coatings used for land based hot section components fall into the categories of corrosion/oxidation resistant and thermal barrier. As the name implies, the former is applied for corrosion and oxidation protection, while the latter is used to reduce the heat transfer between the gas stream and the substrate of the coated component.

The corrosion/oxidation resistant coatings used in the land based turbines are of two types: diffusion and overlay coatings. Diffusion type coatings include various aluminides and slurry coatings. These coatings are applied by a pack cementation process (PC) or by a chemical vapor deposition (CVD) process. In this type of coating, final coating 
composition depends strongly on the substrate chemistry. Overlay coatings are applied to component surfaces by electron beam physical vapor deposition (EB-PVD), thermal spray techniques such as low plasma spray or vapor plasma spray (LPPS or VPS), high velocity oxy fuel (HVOF) spray, or air plasma spray (APS) processes. Substrate chemistries do not have significant influence on the final compositions of overlay coatings.

Land based turbine manufacturers have been using aluminide type diffusion coatings and MCrAlY (Where $\mathrm{M}$ can be $\mathrm{Ni}, \mathrm{Co}, \mathrm{Fe}$ or a combination thereof) type overlay coatings on the hot section components since the 1970s. The only differences in the use of these coatings by various manufacturers are the selection of minor alloying additions and the methods of application. The use of an efficient cooling scheme permitted Westinghouse to use MCrAlY coatings to about $1650^{\circ} \mathrm{F}$ surface metal temperature with a service life of about 24,000 hours. A development program directed toward advanced corrosion/ oxidation resistant coatings is in progress in Westinghouse to further improve the temperature capability of these coatings. Promising compositions were identified to meet a set of target properties. These compositions are being evaluated in laboratory cyclic corrosion tests and burner rig tests. Westinghouse will select the best available MCrAlY coating for ATS application in terms of temperature capability and long term durability.

TBC will be used to lower the temperatures at the substrate as well as the MCrAlY coating. The most commonly used TBC in land based turbines is yttria-stabilized zirconia (YSZ). The YSZ coating can provide a temperature gradient greater than $100^{\circ} \mathrm{F}$ for a .010 inch thickness, in typical operating conditions. Westinghouse developed a YSZ coating under a DOE program in the 1970 s, and this system, applied predominantly with an APS process, is still used in current turbines. With the advancement of the EBPVD process, it is possible to reduce the coating thickness variation, minimize cooling hole blockage, and especially improve the coating surface finish, which can significantly influence the effectiveness of boundary layer air cooling and the overall TBC performance. But other characteristics, such as foreign object damage and erosion resistance, have yet to be evaluated in comparison with the APS TBC. As part of Phase II, Westinghouse plans to conduct a field engine rainbow test on blades which are coated with both the APS and EB-PVD processes. The results from this engine test will provide more understanding about both the process capability and field performance. A selection of coating process will be made then between the EB-PVD and APS processes to optimize the coating performance versus cost.

Westinghouse field experience indicated that present MCrAlY coatings typically used by the turbine manufacturing industry may not provide a reliable long term protection for the substrate materials at the target RIT of the ATS engine. Since a reliable coating system is critical to the success of meeting the ATS goal, Westinghouse plans to take a three-prong approach to improve the coating reliability.

The first is to develop an advanced bond coat and TBC system that is capable of operating at a $1800^{\circ} \mathrm{F}$ metal temperature for 24,000 hours. Westinghouse has been developing a corrosion-resistant bond coat with an $1800^{\circ} \mathrm{F}$ capability. Tests at $1850^{\circ} \mathrm{F}$ in 
a $\mathrm{Na}_{2} \mathrm{SO}_{4}$ environment have demonstrated the superior environmental resistance of this bond coat as compared to CoNiCrA1Y (RT122). Westinghouse also has identified a series of TBC stabilizers (e.g. $\mathrm{Sc}_{2} \mathrm{O}_{3}$ ), new ceramic compositions and structural modifications aimed at improving the thermal stability, corrosion resistance and spalling resistance of TBC. The investigation of these innovative concepts will be initiated in Phase III.

The second approach is to perform field and laboratory testing to determine the reliability of current coating systems. Westinghouse has been performing field testing of various coated components for several years. Westinghouse will evaluate the reliability of TBC coating applied by air plasma and electron from physical vapor deposition (EB-PVD) on IN738 rotating blades. Because the field testing to date has been carried out in units with relatively low firing temperatures, it is recommended that field testing in a unit with firing temperature closer to that of the ATS, be considered. This testing will determine the long term TBC stability, and bond coat interaction with CMSX-4 and CM247 blade substrates which contain lower $\mathrm{Cr}$ than IN738. Lab testing will also be supplemented to determine the effects of phase change, fatigue, creep and corrosion on TBC spalling.

The third approach is to develop a computer based life prediction model with the ability to predict cycles to failure for bond coat and TBC. Westinghouse has developed a life prediction model for uncoated cast airfoil alloy with excellent results. This model can be extended or modified to include coating systems. A reliable life prediction model for complex coated components will provide a systematic understanding and control of coating degradation and contribute to the more reliable use of coatings. 


\section{Section 6}

\section{CRITICAL COMPONENTS AND BARRIER ISSUES}

In order to achieve the very challenging ATS Program performance and emissions goals, new technologies have to be developed and existing technologies extrapolated beyond the current state-of-the-art. To achieve the required plant efficiency level a considerable improvement in gas turbine engine performance will be necessary. The engine performance enhancement will require an increase in the firing temperature, improvements in aerodynamic design, reduction in cooling flows, and improvement in sealing. All of the above will need technological development and innovation. The higher firing temperature operation will necessitate developments in technologies related to improved materials, such as directionally solidified and single crystal airfoils, improved coatings such as TBC and improved corrosion/oxidation protection coatings, and improved or novel cooling schemes. To reduce combustion emissions at the higher firing temperatures required for the ATS engine, technological developments will be needed in the flow visualization, optical diagnostics, combustion noise, and catalytic combustion fields. To improve the turbine efficiency, active blade tip clearance control system will be developed and brush seal technology will be incorporated in appropriate locations in the compressor and the turbine.

To achieve the ATS Program plant cycle efficiency target of greater than $60 \%$ the following strategy was mapped out. This strategy is based on the advanced combined cycle concept, which will incorporate an advanced engine design, as well as improvements in the bottoming cycle and the generator. The selection of this cycle was based on the consideration of overall plant efficiency, cost of electricity, practicability, reliability-availability - maintainability, and the time frame of the ATS Program. Some of the options considered in the ATS cycle evaluation, such as recuperation, reheat, and thermochemical recuperation, had potentially higher plant cycle efficiency, compared to the advanced combined cycle concept. However, they were not selected for further development due to the reasons stated above.

The main contributor to the achievement of all of the ATS Program objectives will be an advanced gas turbine design, with the enhanced bottoming cycle and high efficiency generator playing a lesser role. Since the main thrust of the ATS Program is to promote and accelerate the development of advanced gas turbines to enhance the U.S. competitive position in the next century, the main Westinghouse effort will be concentrated on gas turbine engine development. The new components and technologies developed in this program will advance the state-of-the-art of gas turbine design to a new plateau. There will be synergism with gas turbine designs in other applications, such that benefits derived from the ATS Program will enhance the performance of gas turbines designed for use in aero, marine, pipeline and industrial applications. If an advanced bottoming cycle is developed in the future, it can be combined with the advanced gas turbine and thus further enhance the ATS plant efficiency. 
The current production engine, the $501 \mathrm{~F}$, represents the latest step change in engine performance. Its output power is $160 \mathrm{MW}$ and its simple cycle efficiency is about $36 \%$. In a combined cycle application its efficiency is in excess of $54 \%$. This performance level was achieved by approximately $200^{\circ} \mathrm{F}$ increase in firing temperature, advanced aerodynamic design of both the compressor and the turbine, enhanced cooling design of hot end components, and improved materials.

Westinghouse introduced this past spring its latest engine model, the $501 \mathrm{G}$, with an output power of about $230 \mathrm{MW}$ and a net combined cycle efficiency of about $58 \%$. The large improvement in efficiency results from a further $250^{\circ} \mathrm{F}$ increase in firing temperature and advancements in aerodynamic design, cooling design, and hot end materials.

The ATS engine will represent a revolutionary development. To achieve the required improvement in efficiency to meet the plant cycle efficiency target of greater than $60 \%$, will require additional advances in aerodynamic design, heat transfer, and materials technologies. To ensure that the above goal is achieved the following improvements will be incorporated:

\section{Engine}

1. Advanced aero/heat transfer/materials technology

2. BOT $>2730^{\circ} \mathrm{F}$

3. Closed-loop steam cooling

4. Single crystal and directionally solidified airfoils

5. Improved thermal barrier and anti-corrosion coatings

6. Ceramic ring segments

$7 \quad$ Active tip clearance control

8 Brush seals

9. Reduced compressor dump/combustor loss

10. Increased Row 4 blade exit area

\section{$\underline{\text { Plant }}$}

1. Reduced inlet/exhaust losses

2. Fuel preheating

3. Single shaft: Combustion Turbine - Generator - Steam Turbine

4. Advanced steam turbine design technology

5. $\quad 1800 \mathrm{psi}, 1100^{\circ} \mathrm{F} / 1100^{\circ} \mathrm{F}$ steam cycle

The latest state-of-the-art aerodynamic, heat transfer and materials technologies will be employed in the design of the ATS engine. The burner outlet temperature will be between $2730^{\circ} \mathrm{F}$ and $2800^{\circ} \mathrm{F}$, so as to produce high cycle efficiency and still allow the emissions goals to be met. To help in achieving low NOx emissions at the high burner outlet temperatures, catalytically enhanced combustor components will be employed. 
To optimize plant cycle efficiency closed-loop steam cooling will be employed on the hot end components, such as transitions, Rows 1 to 3 vanes, Rows 1 and 2 blades, and some of the blade rings. Single crystal casting technology will be employed on Rows 1 to 3 blades and directionally solidified casting technology on Row 1 vane. Improved or advanced alloys will be used in these castings. Improved thermal barrier and anti corrosion/oxidation coatings will be applied to the turbine airfoils to allow long term operation at surface metal temperatures approaching $1800^{\circ} \mathrm{F}$. Ceramic ring segments (stationary shrouds located above the blade tips) on Rows 1 and 2 will be incorporated.

Active tip clearance control will be developed for Rows 1 and 2 turbine blades to reduce blade tip leakage losses. This will result in an improvement in efficiency and significantly reduce the turbine performance deterioration with operating time, because of prevention of tip rubs. To reduce leakage, as well as hot gas ingestion into turbine disc cavities, brush seals will be installed in appropriate locations in the turbine and compressor.

As a result of flow tests at Clemson University on a model of a combustion cylinder and the elimination of showerhead cooling on turbine airfoils, the compressor exit dump loss and the combustor pressure loss will be reduced significantly. To reduce the turbine exhaust diffuser losses, the Row 4 turbine exit area will be increased by about $12 \%$ compared to that of the latest design.

To achieve the overall efficiency objective, improvements are planned in the plant design. Inlet and exhaust systems will be designed so as to minimize the duct losses without incurring excessive costs. Fuel preheating will be employed to optimize the utilization of exhaust heat. The single shaft concept will be used, with the gas turbine, the generator and the steam turbine connected together. The high efficiency generator will be designed specifically for the ATS plant. Advanced aerodynamic design technology will be applied to the steam turbine design to optimize its efficiency. A three-pressure level steam cycle, with 1800 psi and $1100^{\circ} \mathrm{F}$ high pressure steam and $1100^{\circ} \mathrm{F}$ reheat steam, will be employed. Figure 6-1 shows the ATS plant schematic layout.

With the planned improvements in the gas turbine and plant design, the estimated ATS plant cycle efficiency will be approximately $62 \%$. To achieve this efficiency level will require an extensive development effort in all of the major gas turbine technologies. To expedite this development new research and development projects are planned, in addition to those projects already in progress under Task 8 of Phase 2 of the ATS Program. These projects are grouped under the following main headings: combustion, cooling, mechanical design, leakage control, and materials/coatings. These projects are listed in Table 6-1. 
TABLE 6-1

ATS COMPONENT DEVELOPMENT PROJECTS

\begin{tabular}{|c|c|}
\hline TECHNOLOGY & PROJECTS \\
\hline I Combustion & $\begin{array}{l}\text { Flow Visualization } \\
\text { Optical Diagnostics Probe } \\
\text { Combustion Noise Investigation } \\
\text { Catalytic Combustion }\end{array}$ \\
\hline $\begin{array}{ll}\text { II } & \text { Cooling }\end{array}$ & $\begin{array}{l}\text { Airfoil/Shroud Cooling } \\
\text { Integral Shroud Cooling } \\
\text { Serpentine Channel Cooling } \\
\text { Closed-loop Steam Cooling }\end{array}$ \\
\hline Mechanical Design & Last Row Turbine Blade \\
\hline IV Leakage Control & $\begin{array}{l}\text { Active Tip Clearance Control } \\
\text { Brush Seals }\end{array}$ \\
\hline V $\quad$ Materials/Coatings & $\begin{array}{l}\text { Directionally Solidified Casting } \\
\text { Single Crystal Castings } \\
\text { Thermal Barrier Coatings } \\
\text { Ceramic Components }\end{array}$ \\
\hline
\end{tabular}

\section{ATS COMPONENT DEVELOPMENT PROJECTS}

\section{Combustion}

Due to the higher firing temperatures, and the strict emissions requirements for the ATS engine, combustion development will be one of the critical areas requiring significant effort and expenditure of very large sums of money. To address this issue, the following combustion development programs are planned: combustor flow visualization, combustion optical dignostics probe development, combustion instability/noise investigation, and catalytic combustion components development.

Air flows inside the combustor cylinder and into the combustor baskets are very complicated. These flows have a very significant effect on the losses, and hence on engine performance, and on the flow distribution inside the combustor baskets, and hence on the combustion processes. The latter effect is especially critical in the dry ultra low NOx lean premix combustors, which rely on the correct fuel/air ratios, within a very narrow tolerance band, for low NOx production and operational flame stability. Flow 
tests will be carried out on plastic models of the ultra low NOx baskets in the single can rig and the sector rig. Flow visualization and detail flow mapping tests will be done. Hot wire anemometry as well as conventional measurement techniques will be employed.

Flow mapping and flow visualization tests will be carried on a half scale plastic model of the $501 \mathrm{~F}$ combustor cylinder at Clemson University. Higher order flow effects inside the combustor cylinder will be investigated. Detail information on pressure, velocities and flow angles inside combustor cylinder, and especially around the combustor baskets, will be obtained. Included in this investigation will be the effect of struts, cooling air bleed port, cooling air return pipes, diffuser exit swirl, modulation of the by-pass valve, flow shields around the combustor baskets, top hat length, ultra low NOx basket, and curved compressor exit diffuser. In addition to studying and optimizing the flow around the combustor baskets, the objective of these tests is to optimize the performance of the compressor exit diffuser, reduce the diffuser exit dump loss, and hence improve the ATS engine performance.

Optical diagnostics allow measurement of pertinent parameters, such as the composition and concentration of combustion products, in addition to velocities and flow angles, without disturbing the main flow. An optical diagnostic probe needs to be developed to aid in combustion system optimization. Rig and engine tests, using the optical diagnostic probe, will need to be carried out.

To achieve the very challenging performance goals of the ATS program, high firing temperatures will be required. This will make the achievement of the NOx emissions goals that much more difficult. Lean premix combustion systems will have to be employed. The very lean combustion, with its inherent flame instability, will result in more combustion generated noise, and hence in vibration problems in the combustion system as well as in the downstream components. A program is needed to develop the theoretical background on combustion instabilities, carry out experiments to aid in the understanding of the problem, develop a generalized analysis procedure, and develop stability criteria for a particular combustor basket.

Due to an increase in NOx production with increasing flame temperature, catalytically enhanced combustion will play an important role in achieving ultra low NOx emissions at firing temperatures in the range of $2500^{\circ} \mathrm{F}$ and higher. The advantage provided by the catalyst is that it allows ultra lean premix (fuel and air) combustion without resulting in flame instability and flame outs. Hence, the result is NOx production in low single digits at higher firing temperatures with stable combustor operation. A development program is needed to gain theoretical understanding of catalytic combustion, to design a catalytic combustion system using the "clean sheet approach," and to develop a practical catalytic combustor. A preliminary investigation is necessary, and combustor baskets with catalytic components need to be developed. 


\section{Cooling}

The development of new cooling technologies will be of paramount importance to the success of the ATS Program. The increased firing temperature will require cooling of components which previously did not need cooling and a significant improvement in cooling technology of previously cooled components. Closed-loop steam cooling will be used on most of the hot end components because of the resulting large increase in plant cycle efficiency. However, film cooling tests will be continued as a back-up, in case closed-loop steam cooling does not provide adequate cooling on some components such as the trailing edge regions of the Row 1 vane.

The airfoil end walls or shrouds present a cooling design challenge even at current firing temperatures. Model tests are needed to optimize the cooling design of vane shrouds. Even with closed-loop steam cooling sections of the Row 1 vane may have to be film cooled. To address this issue model tests can be used to optimize vane suction surface film cooling design.

In order to improve performance and reduce blade vibratory stresses, the Row 3 turbine blade will incorporate an integral interlocked tip shroud as used on the $501 \mathrm{~F}$ and $501 \mathrm{G}$ engines. The tip shroud and the very large blade height may make it very difficult to develop the SC casting process in time for the first ATS engine. As a back-up, the blade will be designed with cooling to maintain the blade metal temperature at an acceptable level. To cool this long, highly twisted blade will be quite a challenge. It will be especially difficult to cool the tip shroud. The development of a viable tip shroud cooling scheme will be carried out. Alternative cooling designs and manufacturing processes will be evaluated. Blade casting development program of the selected design will be carried out.

In order to maintain blade metal temperatures at acceptable levels at the firing temperature required to achieve the ATS program plant efficiency objective, complicated multi-pass serpentine cooling schemes will be developed. Plastic model tests will be carried out on the selected serpentine channel cooling schemes to verify and optimize the design prior to incorporation into the engine. Two models will be tested: one model simulating the multi-pass mid chord region of the blade, and the second model representing the trailing edge portion of the blade. Tests will be carried out at different cooling air flow rates. The internal heat transfer coefficients and pressure losses will be measured.

The one modification that will result in the greatest improvement in the ATS plant cycle efficiency is closed-loop steam cooling. The heat capacity of steam is about 1.3 times that of air. Therefore less steam would be required to cool the hot end components than air. Closed-loop steam cooling will eliminate the surface ejection of the cooling air and hence the mixing losses. This will result in an improvement in stage efficiency. Elimination of Row 1 vane cooling air ejection into the main stream will result in an increase in Row 1 turbine blade inlet temperature and the turbine exhaust temperature for 
the same bumer outlet temperature. The combination of the above effects will increase the ATS plant efficiency significantly. There are several challenges to be overcome before a successful closed-loop steam cooling systems is developed. These include maintaining acceptable airfoil surface metal temperatures without outside film cooling, high wall temperature gradients, effect of steam on metal components over long periods of time, bringing steam to and out of rotating components, leakages, and cold start before steam from the downstream HRSG is available.

\section{Mechanical Design}

The last row turbine blade is another component requiring a susbstantial development effort. To achieve minimum exhaust losses, the annulus area of the last row turbine blade must be as large as possible. This results in a long highly stressed last row blade. To avoid excessive vibratory stresses, this blade incorporates an integral interlocked tip shroud. In this type of a blade design, there is a possibility that two blade natural frequencies may occur between adjacent harmonics. These two frequencies can become coupled, and the resulting vibratory stresses can cause blade failure. To develop a successful last row blade design a three phase program is needed. The initial task will consist of a preliminary investigation, which will cover a review of the design rules for last row turbine blades, the reevaluation of advantages/disadvantages of interlocked shroud versus free standing last row blades, and the evaluation of the effect of stimuli and damping on last row blade vibratory stresses. The next step will consist of the evaluation of alternative blade and shroud designs, including part span shrouds, and a blade casting development program on the selected design. Finally, a vibration test of the last Row blade will be carried out to verify the design. The Blade Vibration Monitoring (BVM) technique, developed by Westinghouse, will be employed to measure vibration characteristics of individual blades.

\section{Leakage Control}

Turbine blade tip clearance has a very significant effect on the performance of highly loaded front stages. For each $1 \%$ tip clearance increase (based on blade height) the stage efficiency may decrease by up to $2 \%$. For a four-stage turbine this will result in about $1 / 2 \%$ decrease in overall turbine efficiency. Even if the initial cold blade tip clearances are set at minimum values, during transients, such as rapid starts and emergency shutdowns, the blade tips are ground off. This results in increased hot running blade tip clearances, which get progressively worse with time. An active tip clearance control system will be developed to solve this problem. The objective of such a scheme would be to maintain large tip clearances on start up and to reduce them to minimum acceptable values when the engine has reached the steady state operating condition. This can be accomplished by cooling, at appropriate times, the blade ring holding the ring segments located above the rotating blade tips. A conceptual design of an active tip clearance control system will be made. Field tests on a host engine will be required to verify the viability of the concept. 
To reduce air leakage, as well as hot gas ingestion into turbine disc cavities, brush seals can be incorporated in appropriate locations in the turbine and compressor. This will result in an improvement of engine efficiency as well as mechanical integrity of the turbine components. The incorporation of an effective, reliable, and long-lasting brush seal system into a heavy duty industrial combustion turbine will require a development effort. To achieve this, a three phase program is suggested. Phase 1 will involve preliminary investigation and a conceptual brush seal design, in Phase 2 brush seals for specific engine locations will be manufactured, and in Phase 3 performance and endurance tests will be carried out on brush seals incorporated into a suitable host engine.

\section{Materials/Coating Development}

Considerable improvements in engine performance and reliability will be derived from improved materials and coatings. Development of single crystal and directionally solidified airfoil casting technology for the ATS engine will be a necessity. A program is currently underway to evaluate CMSX-4 alloy for single crystal blade castings. A development program will be carried out on the castability of CM247 LC alloy for directionally solidified Row 1 vane castings.

Ceramic thermal barrier coatings (TBC) are useful in reducing metal temperatures of actively cooled gas turbine components. The low thermal conductivity of TBC's effectively insulates the metal substrate and provides approximately $20^{\circ} \mathrm{F}$ to $25^{\circ} \mathrm{F}$ metal temperature reduction per one thousandth of applied coating. While TBC's have been used widely on stationary components, use on rotating components has been limited due to reliability concerns, such as degradation from foreign object damage, erosion, and cyclic loading. Field testing of coated blades will be carried out to determine comparative coating longevity and effectiveness of air plasma spray and physical vapor deposition thermal barrier coatings. 


\section{Section 7}

\section{REFERENCES}

Baldwin, C.J., Boho, M.J., Beeley, E.W. and Stephens, J.O., 1965, "Future Role of Ga Turbines in Power Generation, "Proceedings American Power Conference, Vol. 27, pp. 484-500.

Bannister, R.L., Cheruvu, N.S., Little, D.A. and McQuiggan, G., 1994, "Development Requirements for an Advanced Gas Turbine System," ASME Paper 94-GT-388.

Ernette, D.J. and Silvestri, G.J., 1990, "Optimized Steam Cycle Configurations for Subcritical Applications," ASME Paper 90-JPGC/Pwr-5.

Little, D.A., Bannister, R.L. and Wiant, B.C., 1993, "Development of Advanced Turbine Systems," ASME Cogen Turbo Power '93 Proceedings IGTI-Vol.8, pp. 271-280

Scalzo, A.J., Bannister, R.L., DeCorso, M. and Howard, G.S., 1994, "Evolution of Heavy-Duty Power Generation and Industrial Combustion Turbines in the United States," ASME Paper 94-GT-488.

Silvestri, G.J., Bannister, R.L., Fujikawa, T. and Hizume, A., 1992, "Optimization of Advanced Steam Condition Power Plants," Transactions of the ASME, Journal of Engineering for Gas Turbines and Power, Vol. 114, pp. 612-620.

Stephens, J.O., 1952, "Gas Turbine Power Plant Designs," Proceedings American Power Conference, Vol. 14, pp. 267-271. 


\section{Appendix A}

\section{CAPITAL COST AND COE ASSUMPTIONS}

\section{CODE OF ACCOUNTS}

A Code of Accounts was developed to provide the required structure for the ATS estimate. The Code facilitates the consistent allocation of individual costs that were developed and is similar to other estimate code structures to permit future cost comparisons if desired. The Code facilitates recognition of estimated battery limits and the scope included in each account. This Code is presented in Table A-1, along with a listing of scope included in each account.

Table A-1

Code of Direct Accounts Summary

Account Number Account Title

PRIMARY FUEL SUPPLY

Natural Gas Supply Piping

FUEL PREPARATION AND TREATMENT

Fuel Heaters

FEEDWATER and MISCELLANEOUS SYSTEMS and EQUIPMENT

(including the following)

Feedwater System

Makeup Treatment, Pretreating, and Storage

Other Feedwater and Condensate Subsystems

Service Water Systems

Other Boiler Plant Systems

Fuel Oil Supply System

Waste Treatment Equipment

Miscellaneous Power Plant Equipment

BOILER, STEAM GENERATOR

Heat Recovery Steam generator

HRSG Accessories

Recuperator/ Reformer and Accesories

HOT GAS CLEANUP and HOT GAS PIPING

(Not Used)

6

COMBUSTION TURBINE and ACCESSORIES

Combustion Turbine Generator

Combustion Turbine Accessories

Compressed Air Piping

Foundations and Supports

7

EXHAUST DUCTWORK and STACK

Ductwork (incl FGD, if used)

Stack

Foundations 
Table A-1 (Continued)

STEAM TURBINE GENERATOR, and AUXILIARIES

Steam Turbine Generator and Accessories

Turbine Plant Auxiliaries

Condenser and Auxiliaries

Steam Piping

Foundations

9

COOLING WATER SYSTEM

Cooling Towers

Circulating Water Pumps

Circulating Water System Auxiliaries

Circulating Water Piping

Make-Up Water System

Component Cooling Water System

Circulating Water Foundations and Structures

ASH/SPENT SORBENT RECOVERY and HANDLING

(Not Used)

ACCESSORY ELECTRIC PLANT

Generator Equipment

Station Service Equipment

Switchgear and Control Equipment

Conduit and Gable Tray

Wire and Cable

Protective Equipment

Standby Equipment

Main Power Transformer

Foundations

INSTRUMENTATION and CONTROL

Combustion Turbine Control Equipment

Steam Turbine Control Equipment

Other Major Component Control Equipment

Signal Processing Equipment

Control Boards, Panels, and Racks

Computer and Auxiliaries

Instrument Wiring and Tubing

Other Instrumentation and Controls Equipment

IMPROVEMENTS TO SITE

Site Preparation

Site Improvements

Site Facilities

14

BUILDINGS and STRUCTURES

Gas Turbine Building

Steam Turbine Building

Administration Building

Circulating Water Pumphouse

Water Treatment Buildings

Machine Shop

Warehouse

Other Buildings and Structures 


\section{Capital Costs}

The capital cost, specifically referred to as Total Plant Cost (TPC) for the mature power plant, was estimated using the Electric Power Research Institute (EPRI) structure. The major components of TPC consist of bare erected cost, engineering and home office overheads and fee plus contingencies.

The capital cost for each case was determined through the process of estimating the cost of every significant piece of equipment, component, and bulk quantity on the basis of the baselines previously noted.

\section{Bare Erected Cost}

The bare erected cost level of the estimate, also referred to as the sum of process capital and general facilities capital, consists of the cost of: factory equipment, field materials and supplies, direct labor, indirect field labor, and indirect construction costs. Estimated costs for the major components were established on the basis of vendor data, in-house cost data and support data from previous reports. The general process of estimating the major equipment and system costs consisted of adjusting baseline plant item costs on the basis of exponent relationships. These relationships considered changes in capacity, volumetric flow, pressure and temperature. Results were then verified by comparison to other in-house costs data and relationships. The emphasis of this approach was to reflect relative cycle differences and yield accurate relative cost results that are indicative of cycle generic differences. Other equipment, minor secondary systems, and materials were estimated by Gilbert/Commonweath (G/C) on the basis of in-house data consisting of other project cost data and relationships, catalog data, and standard utility unit cost data.

The labor cost to install the equipment and materials was estimated on the basis of established labor relationships. Labor costing was determined on a multiple contract labor basis with the labor cost including direct and indirect labor costs plus fringe benefits and allocations for contractor expenses and markup. This was supplemented in many cases with equipment labor relationship data to determine the labor cost.

The indirect labor cost was estimated at $7 \%$ of direct labor to recognize the cost of construction services and facilities not provided by the individual contractors. The latter cost represents the estimate for miscellaneous temporary facilities such as construction road and parking area construction and maintenance, installation of construction power, installation of construction water supply and general sanitary facilities, and general and miscellaneous labor services such as jobsite cleanup and construction of general safety and access items. 


\section{Total Plant Cost (TPC)}

The TPC level of the estimate consists of the bare erected cost plus engineering and contingencies. The engineering costs represent the cost of architect/engineer (A/E) services for design, drafting, and project construction management services. The cost was determined at $6.5 \%$ applied to the bare erected cost on an individual account basis. The cost for engineering services provided by the equipment manufacturers and vendors is included directly in the equipment costs.

Allowances for process and project contingencies are also considered as part of the TPC. Some of the process technology used in the various systems is still in the development stage. Continuing process development tends to increase the cost of plant components as problems are discovered and resolved. In an attempt to account for the uncertainty in equipment design, performance, and cost, a process contingency was added to the estimated cost of pertinent components and systems.

Consistent with conventional power plant practices, a general project contingency was added to the total plant cost to cover project uncertainty and the cost of any additional equipment that could result from a detailed design. Based on EPRI criteria, the cost estimate contains elements of Classes I, II, and III level estimates. As a result, on the basis of the EPRI guidelines, a nominal value of $15 \%$ was used to arrive at the plant nominal cost value. This project contingency is intended to cover the uncertainty in the cost estimate itself, Whereas the process contingency covers the uncertainty in the technical development level of specific equipment. In both cases the contingencies represent costs that are expected to occur.

This process was repeated for each case evaluated.

In addition to the TPC cost level, the Total Plant Investment (TPI) and Total Capital Requirement (TCR) were determined for each case.

\section{Capital Cost Estimate Exclusions}

Although the estimate is intended to represent complete plants, there remain several qualifications/exclusions as follows:

- Sales tax is not included.

- Allowances for unusual site conditions (such as piling, extensive site access, excessive dewatering, extensive inclement weather) are not included.

- Switchyard (transmission plant) is not included. The cost-estimated scope terminates at the high side of the main power transformer. 
- $\quad$ Royalties are not included.

- No natural gas metering station included (assumed to be provided by the gas supplier at the fence line).

- Disposal costs are not included (considered to be minimal).

\section{Total Plant Investment (TPD)}

TPI at date of startup includes escalation of construction costs and allowance for funds used during construction (AFDC), formerly called interest during construction, over the construction period. TPI is computed from the TPC, which is expressed on an "overnight" or instantaneous construction basis. For the construction cash flow, a uniform expenditure rate was assumed, with all expenditures taking place at the end of the year. Given TPC, cash flow assumptions, nominal interest, and escalation rates, TPI was calculated using:

where:

$$
\mathrm{TPI}=\mathrm{TPC} \times \mathrm{A}\left[\left(\mathrm{R}^{3}-1\right) /(\mathrm{R}-1)+\left(\mathrm{R}^{3}\right) / 2\right]
$$

$$
\begin{aligned}
& A=\% \text { cost expended per year } \\
& R=\text { Compound adjustment factor }=(1+i) /\left(1+e_{a}\right) \\
& i=\text { Weighted cost of capital, } 10.8 \% \\
& e_{a}=\text { Inflation rate, } 4 \%
\end{aligned}
$$

The apparent escalation rate and the weighted cost of capital (discount rate) are the standard values currently proposed by EPRI.

\section{Total Capital Requirement (TCR)}

The TCR includes all capital necessary to complete the entire project. TCR consists of TPI, prepaid royalties, pre-production (or startup) costs, inventory capital, initial chemical and catalyst charge, and land cost:

- Royalties costs are assumed inapplicable to the mature plant and thus are not included.

- $\quad$ Pre-production U.S. costs are intended to cover operator training, equipment checkout, major changes in plant equipment, extra maintenance, and inefficient use of fuel and other materials during plant start-up. They are estimated as follows:

- 1 month of fixed operating costs -- operating and maintenance labor, administrative and support labor, and maintenance materials.

- 1 month of variable operating costs as full capacity (excluding fuel) - includes chemicals, water, and other consumables and waste disposal charges. 
- $\quad 25 \%$ of full capacity fuel cost for 1 month - covers inefficient operation that occurs during the start-up period.

- $\quad 2 \%$ of TPI - covers expected changes and modifications to equipment that will be needed to bring the plant up to full capacity.

- Inventory capital is the value of inventories of fuel, other consumables, and by-products, which are capitalized and included in the inventory capital account. The inventory capital is estimated as follows: Fuel inventory is based on full-capacity operation for 60 days. Inventory of other consumables (excluding water) is normally based on full-capacity operation at the same number of days as specified for the fuel. In addition, an allowance of $1 / 2 \%$ of the TPC equipment cost is included for spare parts.

- Initial catalyst and chemical charge covers the initial cost of any catalyst or chemicals that are contained in the process equipment (but not in storage, which is covered in inventory capital).

- Land cost is based on 12.5 acres.

\section{OPERATING COSTS AND EXPENSES}

The operating costs and related maintenance expenses (O\&M) described in this section pertain to those charges associated with operating and maintaining the power plant over its expected life

The costs and expenses associated with operating and maintaining the plant include:

- Operating labor

- Consumables

- Maintenance (material \& labor)
- $\quad$ By-Product credit (if applicable)

- Administrative and support labor

- Fuel cost

The values for these items were determined consistent with EPRI TAG methods. These costs and expenses are estimated on a first-year basis, in December 1993 dollars. The first-year costs assume normal operation and do not include the initial start-up costs.

The operating labor, maintenance material and labor, and other labor-related costs are combined and then divided into two components; fixed O\&M, which is independent of power generation, and variable $O \& M$, which is proportional to power generation. The first-year operating and maintenance cost estimate allocation is based on the plant capacity factor. 
The other operating costs, consumables and fuel, are determined on a daily $100 \%$ operating capacity basis and adjusted to an annual plant operation basis.

The development of the actual values was performed on a $\mathrm{G} / \mathrm{C}$ model that is consistent with TAG. The inputs for each category of operating costs and expenses are identified in the succeeding subsections along with more specific discussion of the evaluation processes.

This section describes the approach, basis, and methods that were used to perform operating cost evaluations of the power plants. Included in this section are descriptions of:

- Operating Labor

- Maintenance
- Consumables

- Fuel costs

Each of these expenses and costs is determined on a first-year basis and subsequently levelized over the life of the plant through application of a levelizing factor to determine the value that forms a part of the economic evaluation. This amount, when combined with fuel cost and capital charges, results in the figure of merit, or Cost of Electricity (COE).

\section{Operating Labor}

The cost of operating labor was estimated on the basis of the number of operating jobs (OJ) required to operate the plant (on an average-per-shift basis). The operating labor charge (OLC) expressed in first year $\$ / \mathrm{kW}$ was then computed using the average labor rates:

OLC $=\frac{(\mathrm{OJ}) \times(\text { labor rate } \times \text { labor burden }) \times(8760 \mathrm{~h} / \mathrm{yr})}{\text { (net capacity of plant at full load in } \mathrm{kW})}$

The operating labor requirements were determined on the basis of in-house representative data for the major plant sections.

\section{Maintenance}

Annual maintenance costs, according to EPRI's methods, are estimated as a percentage of the installed capital cost. The percentage varies widely, depending on the nature of the processing conditions and the type of design.

On the basis of $\mathrm{G} / \mathrm{C}$ in-house data and EPRI guidelines for determining maintenance costs supplementing previous maintenance evaluations, representative values expressed as a percentage of system cost were specified for each major system. The rates were applied against individual estimate values. Using the corresponding TPC values, a total annual 
(first year) maintenance cost was calculated, including both material and labor components.

Since the maintenance costs are expressed as maintenance labor and maintenance materials, a maintenance labor/materials ratio of $40 / 60$ was used for this breakdown. The operating costs, excluding consumable operating costs, are further divided into fixed and variable components. Fixed costs are essentially independent of capacity factor and are expressed in $\$ / \mathrm{kW}$-yr. Variable costs are incremental, directly proportional to the amount of power produced, and expressed in mills $/ \mathrm{kWh}(\$ / \mathrm{MWh})$. The equations for these calculations are:

Fixed O\&M $=$ Capacity Factor $(\mathrm{CF}) \times$ Total O\&M $(\$ / \mathrm{kW}-\mathrm{yr})$
Variable O\&M $=\frac{(1-\mathrm{CF}) \times \text { Total O\&M }(\$ / \mathrm{kW}-\mathrm{yr}) \times 1000 \mathrm{mills} / \$}{(\mathrm{CF} \times 8760 \mathrm{~h} / \mathrm{yr})}$

\section{Consumables}

The feedstock and disposal costs are those consumable expenses associated with this plant operation. Consumable operating costs are developed on a first-year basis and subsequently levelized over the 30-year life of the plant. The consumables category consists of water, chemicals, other consumables, and waste disposal.

The water component pertains to the water acquisition charge for water required for the plant steam cycle, and for miscellaneous services.

The chemicals component consists of:

- A composite water makeup and treating chemicals requirement in which unit cost and the ratio of chemicals to water were based on data from comparable plants

- The liquid effluent chemical category, representing the composite chemical requirement for wastewater treating, in which unit cost and quality were developed similar to the water makeup and treating chemicals

- The catalyst required for reforming.

The other consumables component consists of gases, primarily the nitrogen required for transport and blanketing. The results of the evaluation of the individual categories of O\&M expenses for each case were summarized on separate tables (Capital Investment and Revenue Requirement Summary, along with summary TPC, TPI and TCR values).

These summary tables also included the annual fuel cost and levelized COE and constituent values of $\mathrm{COE}$. A discussion of the basis for determining these values is 
included. The unit cost for gases was based on pricing furnished by an industrial gas supplier.

\section{Fuel Cost}

The fuel (natural gas) cost used is $\$ 3.00 / 10^{6} \mathrm{Btu}$, the plant net heat rate Btu/kWh (HR) and the higher heating value (HHV) of $23,880 \mathrm{Btu} / \mathrm{lb}$. For the fuel as well as for all feedstock and disposal costs, the quantity per day represents the $100 \%$ capacity requirement, while the annual cost values are adjusted for the designated $90 \%$ plant capacity factor. The calculation of first year fuel cost occurred as follows:

Fuel $(2000 \mathrm{cf} /$ day $)=$ HR $\times \mathrm{kW}$ (plant new capacity) $\times 24$ hours HHV $\times 2000 \mathrm{lb} /$ ton

Fuel Unit (per 2000cf) Cost $=\frac{\text { HHV } \times 2000 \mathrm{cf} / \text { ton } \times \mathrm{FC}}{1 \times 10^{6} \mathrm{Btu}}$

Fuel Cost $(1 \mathrm{st}$ year $)=$ Fuel $(\mathrm{t} / \mathrm{d}) \times$ Fuel Unit Cost $(\$ / \mathrm{t}) \times 365$ days $\times 0.90$ (capacity factor) + First-year Cost of Secondary Fuel

The results of individual categories of O\&M expense evaluations for each case were summarized on separate tables. These summary tables also include annual fuel cost, levelized $\mathrm{COE}$, and values of $\mathrm{COE}$ constituents.

\section{COST OF ELECTRICITY}

The revenue requirement method of performing an economic analysis of a prospective power plant is widely used in the electric utility industry. This method permits the incorporation of the various dissimilar components for a potential new plant into a single value that can be compared to various alternatives. The revenue requirement figure-of-merit is COE that is the levelized (over plant life) coal pile-to-busbar cost of power expressed in mills $/ \mathrm{kWh}$. The value, based on EPRI definitions and methods, includes the TCR, which is represented in the levelized carrying charge (sometimes referred to as the fixed charges), levelized fixed variable operating and maintenance costs, levelized consumable operating costs, and the levelized fuel cost.

A consolidated basis for calculating capital investment and revenue requirements was made. The principle cost and economics output for this study, the Capital Investment and Revenue Requirement summary presents key TPC values and other significant capital costs operating costs, maintenance costs, consumables, fuel cost and the levelized busbar $\mathrm{COE}$ were established for the cases calculated.

It should be noted that the levelized carrying charge, applied to TCR, establishes the required revenues to cover return on equity, interest on debt, depreciation, income tax, property tax, and insurance. Levelizing factors are applied to the first year fuel, O\&M 
costs, and consumable costs to yield levelized costs over the life of the project. A long-term inflation rate of $4 \% / y r$. was assumed in estimating the cost of capital and in estimating the life cycle revenue requirements for other expenses (except that fuel was escalated at $6.5 \% / y r$.). To represent these varying revenue requirements for fixed and variable costs, a "levelized" value was computed using the "present worth" concept of money based on the assumptions shown in the basis table resulting in a levelized carrying charge of $16.1 \%$ and levelization factor of 1.472 for all other-than-coal and 1.946 for natural gas.

By combining costs, carrying charges, and levelizing factors, a levelized busbar COE for the $90 \%$ design capacity factor was calculated along with the levelized constituent values. The format for this cost calculation is:

Power Cost $(\mathrm{COE})=\frac{(\mathrm{LCC}+\mathrm{LFOM}) \times 1000 \mathrm{mills} / \mathrm{S}+\mathrm{LVOM}+\mathrm{LCM}-\mathrm{LB}+\mathrm{LFC}}{\mathrm{CF} \times 8760 \mathrm{~h} / \mathrm{yr}}$ where:

LCC = Levelized carrying charge, $\$ / \mathrm{kW}$-yr

LFOM = Levelized fixed O\&M, \$/kW-yr

LVOM = Levelized variable O\&M, mills $/ \mathrm{kWh}$

$\mathrm{LCM}=$ Levelized consumable, mills $/ \mathrm{kWh}$

LB = Levelized by-products (if any), mills/kWh

LFC = Levelized fueled costs, mills $/ \mathrm{kWh}$

$\mathrm{CF}=$ Plant capacity factor, $\%$ 


\section{Appendix B}

\section{RELIABILITY, AVAILABILITY, MAINTAINABILITY}

\section{TECHNICAL APPROACH}

The procedure for estimating the availability of a plant is based on combining the availabilities of its major components. Component availability is calculated from the mean time between outages (MTBO) and the mean time to restore to service (MTTR). Outages include planned and unplanned outages. The combined mean time between outages (MTBO) and mean time to restore MTTR for a set of components, each of which has its own MTBO and MTTR, is determined by two reciprocal addition equations:

$$
\begin{aligned}
& \begin{array}{l}
\text { MTTR(Plant) } \\
\quad=\text { Sum(MTTRi/(MTTRi+MTBOi)) / Sum(1/(MTTRi+MTBOi)) }
\end{array} \\
& \text { MTBO(Plant) = } 1 \text { / Sum(1/MTBOi) } \\
& \text { MTBO(Plant) = Mean Time Between Plant Outages, hrs } \\
& \text { MTBOi = Mean Time Between Outages of equipment (i), hrs } \\
& \text { MTTR(Plant) = Mean Time To Restore (Repair or Replace) plant equipment, hrs } \\
& \text { MTTRi = Mean Time To Restore equipment (i), hrs } \\
& \text { Sum(1/(MTTRi+MTBOi)) = The sum of outage frequencies for each equipment } \\
& \quad \text { item (i), 1/hr. } \\
& \text { Sum(1/MTBOi) = The sum of reciprocal MTBO's for each equipment item (i), } 1 / \mathrm{hr} \text {. } \\
& \text { Sum(MTTRi/(MTTRi+MTBOi)) = The sum of outage rates for each equipment } \\
& \text { item (i), hr/hr. }
\end{aligned}
$$

The equipment unavailability (outage) rate is calculated from the plant MTBO and MTTR:

$$
\text { Equip Unavail }=\text { MTTR }(\text { Plant }) /[\text { MTBO }(\text { Plant })+M T T R(\text { Plant })]
$$

The overall plant availability is calculated as 1.00 minus the equipment unavailability figure:

$$
\text { Availability }=1.00-\text { Equip Unavail }
$$




\section{Effects of Power Loss Fraction}

In this simplified analysis, a component outage may result in a partial loss of plant output and the effect of this partial loss is expressed as an artificial increase in effective MTBO. This analysis assumes that loss of the steam turbine portion of the plant causes a partial loss of plant output.

$$
\begin{aligned}
& \mathrm{MTBO}(\text { effective })=\mathrm{MTBO}(\text { basic }) /\left(\mathrm{PLF}^{*} \mathrm{Cp}\right) \\
& \mathrm{MTBO}=\text { Mean Time Between Outages } \\
& \text { PLF }=\text { Power Loss Fraction: fraction of plant power lost if all strings of this } \\
& \quad \text { component fail } \\
& \text { Cp }=\text { Capacity per parallel string (e.g., } 0.5)
\end{aligned}
$$

For two or more components operating in parallel, the power loss fraction is multiplied by the capacity of each parallel component.

\section{Effects of Redundancy}

In this analysis, redundant components are assumed to reduce the probability that component outage will affect the operation of the plant. For example, a plant might have one operating component and one spare for a component that has a $1 \%$ outage rate. The probability of that component failing is 0.01 , but the probability of both components failing is $(0.01) 2=0.0001$. The effect of spare, redundant components is expressed as reduced restoration time:

$$
\begin{aligned}
& \text { MTTR(effective) }=\text { MTBO(basic) } *[(\mathrm{Ue}) /(1-\mathrm{Ue})] \\
& \text { MTTR }=\text { Mean Time To Restore (Repair or Replace) } \\
& \mathrm{U}=\text { Unavailability of basic component }=\mathrm{MTTR} / \mathrm{MTBO}+\mathrm{MTTR}) \\
& \mathrm{e}=\text { Probability exponent }=[(\mathrm{Np} * \mathrm{Cp}-1) / \mathrm{Cp}]+1+\mathrm{Nx}[\text { Integer }] \\
& \mathrm{Np}=\text { Number of parallel strings }(\mathrm{e} . \mathrm{g} ., 2) \\
& \mathrm{Cp}=\text { Capacity per parallel string }(\mathrm{e} . \mathrm{g} ., 0.5) \\
& \mathrm{Nx}=\text { Number of spares (e.g., } 0)
\end{aligned}
$$

The effective redundancy of two or more components operating in parallel depends on whether the total capacity of all streams exceeds $100 \%$. Two $50 \%$ components do not add redundancy, but do add equivalent availability since the unit could operate at $50 \%$ 
capacity while the damaged unit is being repaired. Two $100 \%$ components, on the other hand, effectively add one redundant component. Fractional redundancies are rounded downward.

\section{Availability Spreadsheet}

Plant availability is calculated on a Lotus 2.01 spreadsheet. Summary data for the power plant is presented at the top of the first page, followed by expanded subsystem data. The data in the columns are described below.

No. of Spares: Number of component strings that are not operating, but could be used to cover for an inoperative component string.

Parallel Strings: Number of component strings in the plant.

Capacity per String: Equipment capacity divided by total design capacity requirement. If the capacity per string is greater than $1 /$ (Parallel Strings), the over-capacity is included in plant availability calculations..

Effective Outage Rate: The outage rate for one string of the component as it affects the plant, including the effects of spares, redundancy, and power loss fraction.

Effective MTBO: The mean time between outages (planned and unplanned) of the component as it affects the plant, including the effects of spares, redundancy, and power loss fraction.

Effective MTTR: The mean time to restore (repair or replace) the component as it affects the plant, including the effects of spares, redundancy, and power loss fraction.

Effective 1/MTBO: 1/(Effective MTBO), used in plant summary calculations.

Effective 1/CYCLE: 1/(Effective MTBO + Effective MTTR), used in plant summary calculations.

Total Capacity Loss: The fraction of plant power that is lost if all strings of this component are out of service. Upstream components rate $100 \%$; bottoming cycle components rate less.

Power Loss Fraction: The fraction of plant power that is lost if one string of this component are out of service.

Unit Redundancy Exponent: Probability exponent (see "Effects of Redundancy") used in plant summary calculations. 
Basic MTBO: The mean time between outages (planned and unplanned) for one string of the component. Based on "Baseline Occ/yr" and "Baseline Hrs/Occ" where available; direct input otherwise.

Basic MTTR: The mean time to restore (repair or replace) for one string of the component. Based on "Baseline Occ/yr" and "Baseline Hrs/Occ" where available; direct input otherwise.

Basic Outage Rate: The outage rate for one string of the component.

Baseline Occ/yr: Occurrences per year for the basic unit

\section{SOURCES OF ESTIMATING DATA}

Sources for data used for estimating the availability of the six power generation cases analyzed in the ATS Program included: EPRI Report AP4216, NERC GADS and Westinghouse. Items included in the RAM analysis were:

Primary Fuel Supply,

Fuel Heater,

Feedwater and Miscellaneous Systems,

Boiler/Steam Generator, HRSG,

Recuperator,

Combustion Turbine,

Compressor Evaporative Cooling,

Compressed Air Cooling,

Compressed Air Heater,

Closed-Loop Steam Cooling,

Combustor for High-Pressure Gas Turbine,

High-Pressure Gas Turbine,

Flue Gas Compressor,

Flue Gas Coolers,

Exhaust Ductwork and Stack,

Steam Turbine,

Generator,

Cooling Water System,

Accessory Electric Plant,

Design-Independent Outages 